Article

\title{
Profile and Content of Phenolic Compounds in Leaves, Flowers, Roots, and Stalks of Sanguisorba officinalis L. Determined with the LC-DAD-ESI-QTOF-MS/MS Analysis and Their In Vitro Antioxidant, Antidiabetic, Antiproliferative Potency
}

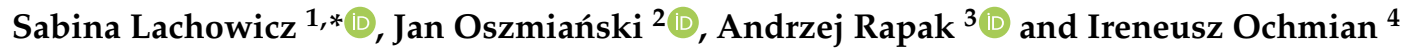 \\ 1 Department of Fermentation and Cereals Technology, Wrocław University of Environmental and Life Science, \\ 51-630 Wrocław, Poland \\ 2 Department of Fruit, Vegetables and Nutraceutical Technology, Wrocław University of Environmental and \\ Life Science, 51-630 Wroclaw, Poland; jan.oszmianski@upwr.edu.pl \\ 3 Laboratory of Tumor Molecular Immunobiology, Ludwik Hirszfeld Institute of Immunology and \\ Experimental Therapy, Polish Academy of Sciences, 53-114 Wrocław, Poland; andrzej.rapak@hirszfeld.pl \\ 4 Department of Horticulture, West Pomeranian University of Technology in Szczecin, \\ 71-434 Szczecin, Poland; ireneusz.ochmian@zut.edu.pl \\ * Correspondence: Sabina.lachowicz@upwr.edu.pl
}

Received: 8 July 2020; Accepted: 3 August 2020; Published: 12 August 2020

\begin{abstract}
The aim of this study was to accurately determine the profile of polyphenols using the highly sensitive LC-DAD-ESI-QTOF-MS/MS technique and to determine in vitro antioxidant activity, the ability of inhibition of $\alpha$-amylase, $\alpha$-glucoamylase, and pancreatic lipase activity, and antiproliferative activity in leaves, flowers, roots, and stalks of medical plant Sanguisorba officinalis L. The results of the analysis of the morphological parts indicated the presence of 130 polyphenols, including 62 that were detected in S. officinalis L. for the first time. The prevailing group was tannins, with contents ranging from $66.4 \%$ of total polyphenols in the flowers to $43.3 \%$ in the stalks. The highest content of polyphenols was identified in the flowers and reached 14,444.97 mg/100 g d.b., while the lowest was noted in the stalks and reached $4606.33 \mathrm{mg} / 100 \mathrm{~g}$ d.b. In turn, the highest values of the antiradical and reducing capacities were determined in the leaves and reached 6.63 and $0.30 \mathrm{mmol} \mathrm{TE} / \mathrm{g} \mathrm{d.b}$, respectively. In turn, a high ability to inhibit activities of $\alpha$-amylase and $\alpha$-glucoamylase was noted in the flowers, while a high ability to inhibit the activity of pancreatic lipase was demonstrated in the leaves of $S$. officinalis $\mathrm{L}$. In addition, the leaves and the flowers showed the most effective antiproliferative properties in pancreatic ductal adenocarcinoma, colorectal adenocarcinoma, bladder cancer, and T-cell leukemia cells, whereas the weakest activity was noted in the stalks. Thus, the best dietetic material to be used when composing functional foods were the leaves and the flowers of S. officinalis L., while the roots and the stalks were equally valuable plant materials.
\end{abstract}

Keywords: in vitro biological activity; bioactive compounds; morphological parts; medical plant

\section{Introduction}

The interest in alternative plants with a health-promoting potential has been growing in recent years not only in the pharmaceutical and cosmetic industries but also in the food industry where they are expected to contribute to the design of novel functional food. Therefore, it is believed that various morphological parts of Sanguisorba officinalis L. represent a good source of compounds exhibiting the aforementioned properties [1]. 
S. officinalis L. (great burnet or burnet bloodwort) is a species belonging to the Rosaceae family. It grows wild in Asia and Europe (except for the northern regions [1,2]. This melliferous, perennial plant usually occurs on arid and semi-arid grasslands and blooms from June till September. Its shoots can grow up to ca. 1.2-1.5 m. S. officinalis L. is resistant to frost as well as to diseases. It has been used for culinary purposes as an additive to salads and in animal feeding as an additive to feed mixtures due to its high nutritional value [3]. However, in folk medicine of both the Far East and Europe, S. officinalis L. was used as an herbal medicine in relieving inflammation, controlling external and internal bleeding, in the treatment of ulcers, burns, eczema, acne, as well as diarrhea [4,5]. In turn, the available experimental data prove a number of its biological properties, e.g., anti-inflammatory [3], anticancer [6], antiviral [7], antioxidant [1], prevention of the Alzheimer's disease [3], and anti-wrinkle effects. [8]. In addition, the above studies have shown that all the biological properties exhibited by this perennial plant are due to a broad range of its bioactive compounds such as phenolic acids, tannins, flavonoids, triterpenes, and polysaccharides [1,3-8]. The richness of these compounds is sought in alternative plant sources that could be used in the treatment and prevention of many diseases and even as a dietary component [9].

Considering a number of biological properties of S. officinalis L., this plant has a high nutraceutical potential. However, there are a few reports on the profile and content of secondary metabolites in all of its morphological parts, which may differ and therefore exhibit various properties. Thus, research was undertaken into the accurate characterization of flowers, leaves, stalks, and roots in terms of the profile and content of polyphenols using the highly sensitive LC-DAD-ESI-QTOF-MS/MS technique. Analyses were also conducted to determine the in vitro antioxidant, antiproliferative, and antidiabetic activity for the individual morphological parts of $S$. officinalis $\mathrm{L}$. This study aims to provide valuable information about differences in contents of bioactive compounds and their biological properties in the flowers, leaves, stalks, and roots of S. officinalis L., which will be used to compose not only functional foods but also nutraceuticals in the future.

\section{Results and Discussion}

\subsection{Identification of Polyphenolic Compounds}

The present study involved a thorough identification of the profile of bioactive compounds in extracts from leaves, flowers, stalks, and roots of Sanguisorba officinalis L. plant with the use of an ultrasensitive LC-DAD-ESI-QTOF-MS/MS method in the negative and positive ion mode. In total, 130 compounds were identified in extracts from the selected morphological parts of $S$. officinalis L., including 77 hydrolyzable tannins, 9 sanguiins, 3 sanguisorbic acids, 13 phenolic acids, 6 anthocyanins, 12 catechins and proanthocyanidins, and 9 flavonols, as well as 1 triterpenoid saponins (Table 1; Figures S1-S4). In turn, 62 compounds were identified in S. officinalis L. for the first time ever, including 42 hydrolyzable tannins, 5 sanguiins, 8 phenolic acids, 2 anthocyanins, 1 proanthocyanidins, and 3 flavonols as well as 1 triterpenoid saponins. Peaks were identified based on the determined exact molecular weights, peak retention times, primary ions from MS fragmentation, and comparison of data obtained with commercial standards and literature findings (Table 1). However, the profile of the compounds examined was strongly dependent on the morphological part of the plant, since 70, 76, 66, and 62 compounds were identified in the flowers, leaves, roots, and stalks, respectively.

The prevailing group of polyphenolic compounds were hydrolyzable tannins belonging to the family of tannins and being hydrolyzed conjugates that contain one or more hexahydroxydiphenoyl (HHDP) groups, thus leading to the esterification of sugars, glucose in particular. During fragmentation of the primary ions, losses observed were typical of these compounds and involved losses of galloyl, hexahydroxydiphenoyl, gallic acid, HHDP glucose, galloyl-glucose, and galloyl-HHDP-glucose residues with 152, 302, 170, 482, 332, $634 \mathrm{Da}$, respectively. Additionally, fragments were noted at $\mathrm{m} / \mathrm{z} 169$ and at $\mathrm{m} / \mathrm{z} 301$ formed through lactonization of the characteristic hexahydroxydiphenoyl group to ellagic acid. These compounds comprise typical galloyl and HHDP groups, respectively, 
which have earlier been described in the available literature [1-3,9-11]. Furthermore, if ellagitannin or galloyl derivates are composed of one or a few galloyl groups taking part in sugar synthesis, the fragmentary ion first discards a molecule of gallic acid and then a galloyl group or groups during fragmentation [10]. Among the 77 compounds, only 36 had previously been identified in S. officinalis L., and they all were methyl-6-O-galloyl- $\beta$-D-glucopyranoside (peak 17,$64 ; m / z 345)$, pedunculagin 1 (18, $23,29 ; \mathrm{m} / \mathrm{z} 785)$, galloyl-HHDP-glucose otherwise called corilagin isomer $(25,44,55 ; \mathrm{m} / \mathrm{z} 633)$, di-galloyl-glucoside (37; $m / z$ 483), methyl-4,6-digalloyl- $\beta$-D-glucopyranoside $(50,62,71,88 ; m / z 497)$, HHDP-galloyl-glucose (53; $m / z$ 633), ellagic acid pentoside $(60,99 ; m / z 433)$, ellagic acid hexoside $(67,68,102 ; \mathrm{m} / \mathrm{z} 463)$, di-galloyl hexoside $(72,118 ; \mathrm{m} / \mathrm{z} 483)$, galloyl-bis-HHDP-glucose otherwise called potentilin/casuarictin isomer $(84,85,95,97,104,106 ; \mathrm{m} / \mathrm{z} 935)$, lambertianin $C(86 ; \mathrm{m} / \mathrm{z} 1401)$, ellagic acid (108; $\mathrm{m} / \mathrm{z}$ 300.99), trigalloyl-HHDP-glucose $(92,114 ; \mathrm{m} / \mathrm{z}$ 937), trigalloyl- $\beta$-D-methyl

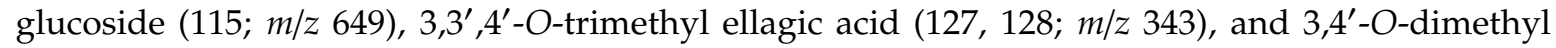
ellagic acid $(129,130 ; \mathrm{m} / \mathrm{z}$ 329) [2,3,12]. In turn, 16 compounds had earlier been detected and identified in flowers and fruits of Punica granatum but in this study were for the first time detected in the morphological parts of $S$. officinalis L. These compounds were referred to as: 2,3-HHDP- $(\alpha / \beta)$-glucose ( $1 ; m / z$ 481), HHDP-hexoside(2,3-(S)-Hexahydroxydiphenoyl-D-glucose) $(2,4 ; m / z$ 481), HHDP-hexoside(1-galloyl-2,3-hexahydroxydiphenoyl- $\alpha$-glucose) $(3 ; \mathrm{m} / z \mathrm{~m}$ 4), galloyl-hexoside( $\beta$-glucogallin) $(5 ; m / z$ 331), galloyl-hexoside $(7-10,13 ; m / z 331)$, di-HHDP-glucoside (34; $m / z$ 783), di-galloyl-HHDP-glucose $(14,56,66 ; m / z ~ 785)$, galloyl-HHDP-hexoside (77; $m / z$ 633), and pentagalloyl-glucoside $(111 ; \mathrm{m} / z$ 939) $[10,13]$. Another 6 compounds belonging to the group of hydrolyzable tannins were detected during identification of Duchesnea indica and they were: di-HHDP-glucose also known as pedunculalagin isomer $(15,20,24,26,27,30 ; \mathrm{m} / \mathrm{z} 783)$ [14]. However, 12 subsequent compounds were identified and determined based on their main ion and MS/MS fragmentation as $\beta$-1-O-galloyl-2,3-(S)-HHDP-D-glucose (28; $\mathrm{m} / \mathrm{z} 633)$, methyl ellagic acid-pentoside (35; $\mathrm{m} / \mathrm{z}$ 477), HHDP-NHTP-glucose $(47,51 ; \mathrm{m} / \mathrm{z}$ 933), castalagin/vescalagin isomer $(58,70,79$, 81, 98, 110; $m / z$ 933), HHDP-NHTP-glucose-galloyl-di-HHDP-glucose (cocciferind2) (82; $m / z$ 933), and tetragalloyl-glucose $(100 ; \mathrm{m} / \mathrm{z} 787)$. They had earlier been detected in various plant materials like Castanea sativa Miller, Quercus suber L., Betula pubescens, raspberry fruits, and oak [15-18]. However, 8 compounds were identified for the first time ever. Compound No. 6 was tentatively identified as galloyl-pentoside based on the primary ion at $\mathrm{m} / \mathrm{z} 301$ and the loss of the pentose group (132 Da) giving a peak at $m / z 169$. Compound No. 49 was tentatively identified as HHDP-glucose based the primary ion at $m / z 481$ and MS/MS fragment at $m / z$ 301. In the case of compound No. 54, the primary peak was at $m / z$ at 345 due to the loss of a 176 Da residue that resulted in a peak formed at $m / z 169$, which was tentatively identified as galloyl-glucoronide. Compounds No. 73 and 74 were tentatively identified as eucaglobulin based on the primary ion at $m / z 497$ and MS/MS fragmentary ions revealing peaks at $m / z 345,327,313,183$, and 169. In turn, compounds No. 93 and 94 were tentatively described as ellagic acid-hexoside-pentoside based the primary ion at $m / z 595$ and its fragmentation ions at $m / z$ 433 and 301 due to the loss of a hexose residue (162 Da) and a pentose residue (132 Da). Finally, compound No. 113 was tentatively identified as methyl galloyl-glucoside based on the primary peak at $m / z 345$ and the loss of a glucosyl residue (162 Da), yielding a base peak at $m / z 183$.

Another described class of polyphenolic compounds belonging to hydrolyzed tannins were sanguiins. Among the 9 identified compounds, only 4 had earlier been detected in S. officinalis L. as sanguiin H-6 $(11,89 ; m / z 1870)$, sanguiin $\mathrm{H}-4(41 ; \mathrm{m} / \mathrm{z} 633)$, and sanguiin H-10 isomer $(48 ; \mathrm{m} / \mathrm{z} 783)$ by Karkanis et al. [3] and Zhu et al. [2], whereas the other 5 were never identified, as shown by literature data. Therefore, based on the primary peak at $m / z 785$ and MS/MS fragmentation peaks at $m / z 633$ and 301, and due to the loss of 152 and 332 Da groups, compounds No. 65, 69, and 96 were tentatively identified as sanguiin H-1. In turn, compounds No. 119 and 122 were tentatively identified as sanguiin $\mathrm{H}-7$ and sanguiin H-7 isomers considering their primary ion at $m / z 801$ and fragmentation peaks at $m / z$ 649 and 301 resulting from the loss of 152, 332, and $16 \mathrm{Da}$. 
Table 1. Characterization of polyphenolic compounds in Sanguisorba officinalis L. by LC-DAD-ESI-QTOF-MS/MS.

\begin{tabular}{|c|c|c|c|c|c|c|c|c|}
\hline No & Compounds & Rt [min] & $\Delta[\mathrm{nm}]$ & MS/MS & $F \ddagger$ & $\mathbf{L}$ & $\mathbf{R}$ & $\mathrm{S}$ \\
\hline \multicolumn{9}{|c|}{ Hydrolyzable Tannins } \\
\hline 1 & 2,3-HHDP- $(\alpha / \beta)$-glucose & 1.31 & 272 & $481 / 463 / 301$ & & & $\mathrm{x}$ & \\
\hline 2 & HHDP-hex(2,3-(S)-Hexahydroxydiphenoyl-D-glucose) & 1.34 & 314 & $481 / 332 / 301 / 182$ & $\mathrm{x}$ & $\mathrm{x}$ & $\mathrm{x}$ & $\mathrm{x}$ \\
\hline 3 & HHDP-hexoside(1-galloyl-2,3-hexahydroxydiphenoyl- $\alpha$-glucose) & 1.41 & 218 & $481 / 301 / 275 / 257 / 229$ & & $\mathrm{x}$ & & \\
\hline 4 & HHDP-hex(2,3-(S)-Hexahydroxydiphenoyl-D-glucose) & 1.50 & 314 & $481 / 330 / 306 / 301 / 203 / 182$ & $\mathrm{x}$ & $\mathrm{x}$ & $\mathrm{x}$ & $\mathrm{x}$ \\
\hline 5 & Galloyl-hexoside( $\beta$-glucogallin) & 1.86 & 278 & $331 / 169$ & & & $\mathrm{x}$ & \\
\hline 6 & Galloyl-pentoside & 1.99 & 274 & $301 / 169$ & & & $\mathrm{x}$ & \\
\hline 7 & Galloyl-hexoside & 2.08 & 272 & $331 / 169$ & & & $\mathrm{x}$ & \\
\hline 8 & Galloyl-hexoside & 2.09 & 268 & $331 / 169$ & & $\mathrm{x}$ & & \\
\hline 10 & Galloyl-hexoside & 2.52 & 278 & $331 / 169$ & & $\mathrm{x}$ & & $\mathrm{x}$ \\
\hline 13 & Galloyl-hexoside & 3.08 & 273 & $331 / 169$ & & $\mathrm{x}$ & & \\
\hline 14 & Di-galloyl-HHDP-glucose (tellimagrandin I) & 3.16 & $236 / 322$ & $785 / 633 / 615 / 483 / 301$ & $\mathrm{x}$ & $\mathrm{x}$ & & $\mathrm{x}$ \\
\hline 15 & Di-HHDP-glucose (pedunculagin isomer) & 3.34 & $230,275 \mathrm{sh}$ & $783 / 481 / 301 / 257$ & $\mathrm{x}$ & $\mathrm{x}$ & $\mathrm{x}$ & $\mathrm{x}$ \\
\hline 17 & Methyl-6-O-galloyl- $\beta$-D-glucopyranoside & 3.54 & 274 & $345 / 169 / 124.99$ & & & $\mathrm{x}$ & $\mathrm{x}$ \\
\hline 18 & Pedunculagin1 & 3.67 & 279 & $783 / 481 / 301$ & $\mathrm{x}$ & & & \\
\hline 20 & Di-HHDP-glucose (pedunculagin isomer) & 3.90 & $230,275 \mathrm{sh}$ & $783 / 481 / 301 / 257$ & $\mathrm{x}$ & & & \\
\hline 23 & Pedunculagin1 & 4.05 & 324 & $783 / 481 / 301$ & $\mathrm{x}$ & & & \\
\hline 24 & Di-HHDP-glucose (pedunculagin isomer) & 4.15 & $230,275 \mathrm{sh}$ & $783 / 481 / 301 / 257$ & $\mathrm{x}$ & & & \\
\hline 25 & Galloyl-HHDP-glucose (corilagin isomer) & 4.18 & $235,280 \mathrm{sh}$ & $633 / 300.99$ & & & $\mathrm{x}$ & \\
\hline 26 & Di-HHDP-glucose (pedunculagin isomer) & 4.24 & 326 & $783 / 481 / 301 / 257$ & & $\mathrm{x}$ & & \\
\hline 27 & Di-HHDP-glucose (pedunculagin isomer) & 4.24 & $230,275 \mathrm{sh}$ & $783 / 481 / 301 / 257$ & $\mathrm{x}$ & & $x$ & \\
\hline 28 & $\beta-1-O-$ galloyl-2,3-(S)-HHDP-D-glucose & 4.30 & 326 & $\begin{array}{l}633 / 617 / 595 / 515 / 454 / 432 / \\
319 / 297 / 179\end{array}$ & $\mathrm{x}$ & $\mathrm{x}$ & & $\mathrm{x}$ \\
\hline 29 & Pedunculagin1 & 4.30 & 279 & $783 / 481 / 301$ & & & $\mathrm{x}$ & \\
\hline 30 & Di-HHDP-glucose (pedunculagin isomer) & 4.40 & 313 & $\begin{array}{l}783 / 613 / 447 / 423 / 274 / 211 / \\
196 / 169\end{array}$ & $\mathrm{x}$ & $\mathrm{x}$ & & $x$ \\
\hline 34 & Di-HHDP-glucoside & 4.54 & 273 & $783 / 481 / 301$ & & & $\mathrm{x}$ & \\
\hline 35 & Methylellagic acid-pentose & 4.55 & 324 & $447 / 315 / 301$ & $x$ & $\mathrm{x}$ & & $\mathrm{x}$ \\
\hline 37 & Di-galloyl-glucoside & 4.59 & 273 & $483 / 313 / 169$ & & & $\mathrm{x}$ & \\
\hline 44 & Galloyl-HHDP-glucose & 4.98 & $219 / 276$ & $633 / 463 / 301$ & $\mathrm{x}$ & $\mathrm{x}$ & $\mathrm{x}$ & $x$ \\
\hline 47 & HHDP-NHTP-glucose (castalagin/vescalagin) & 5.08 & 219 & 933/915/889/871/631/613/587/569 & $\mathrm{x}$ & $\mathrm{x}$ & $\mathrm{x}$ & $\mathrm{x}$ \\
\hline 49 & HHDP-glucose & 5.30 & 222 & $481 / 301$ & $\mathrm{x}$ & $\mathrm{x}$ & $x$ & $x$ \\
\hline 50 & Methyl-4,6-digalloyl- $\beta$-D-glucopyranoside & 5.39 & 212 & $497 / 345 / 169$ & $\mathrm{x}$ & $\mathrm{x}$ & $\mathrm{x}$ & $\mathrm{x}$ \\
\hline 51 & HHDP-NHTP-glucose (castalagin/vescalagin) & 5.44 & $282 / 343$ & $933 / 915 / 889 / 871 / 631 / 613 / 587 / 569$ & & & $\mathrm{x}$ & \\
\hline 53 & HHDP-galloyl-glucose & 5.50 & 318 & 633/463/301/273/257/229/201/185 & $\mathrm{x}$ & & & \\
\hline 54 & Galloylglucoronide & 5.52 & 276 & $345 / 169$ & & & $\mathrm{x}$ & \\
\hline 55 & Galloyl-HHDP-glucose (corilagin isomer) & 5.55 & 218 & $633 / 463 / 301$ & & $\mathrm{x}$ & & \\
\hline 56 & Di-galloyl-HHDP-glucose (tellimagrandin I) & 5.63 & $230,280 \mathrm{sh}$ & $785 / 633 / 615 / 483 / 301$ & $\mathrm{x}$ & $x$ & & \\
\hline 58 & Castalagin/vescalagin isomer & 5.69 & $230,285 \mathrm{sh}$ & 933/915/889/871/631/613/587/569 & $\mathrm{x}$ & $\mathrm{x}$ & & \\
\hline
\end{tabular}


Table 1. Cont

\begin{tabular}{|c|c|c|c|c|c|c|c|c|}
\hline No & Compounds & Rt [min] & $\Delta[\mathrm{nm}]$ & MS/MS & $F \ddagger$ & $\mathbf{L}$ & $\mathbf{R}$ & $S$ \\
\hline 60 & Ellagic acid-pentoside & 5.73 & 330 & $433 / 300.99$ & $\mathrm{x}$ & $\mathrm{x}$ & & $\mathrm{x}$ \\
\hline 62 & Methyl-4,6-digalloyl- $\beta$-D-glucopyranoside & 5.90 & 216 & $497 / 345 / 169$ & $\mathrm{x}$ & $\mathrm{x}$ & $\mathrm{x}$ & $\mathrm{x}$ \\
\hline 64 & Methyl-6-O-galloyl- $\beta$-D-glucopyranoside & 5.97 & 374 & $345 / 169 / 124.99$ & $\mathrm{x}$ & $\mathrm{x}$ & & $\mathrm{x}$ \\
\hline 66 & Di-galloyl-HHDP-glucose (tellimagrandin I) & 6.01 & 203/279 & $785 / 633 / 615 / 483 / 301$ & & & $\mathrm{x}$ & \\
\hline 67 & Ellagic acid hexoside1 & 6.05 & $251 / 362$ & $463 / 301$ & $\mathrm{x}$ & $\mathrm{x}$ & $\mathrm{x}$ & $\mathrm{x}$ \\
\hline 68 & Ellagic acid hexoside & 6.09 & 329 & $463 / 301$ & & & & $\mathrm{x}$ \\
\hline 70 & Castalagin/vescalagin isomer & 6.15 & $230,285 \mathrm{sh}$ & 933/915/889/871/631/613/587/569 & & & $\mathrm{x}$ & \\
\hline 71 & Methyl-4,6-digalloyl- $\beta$-D-glucopyranoside & 6.19 & 213 & $497 / 345 / 169$ & & $\mathrm{x}$ & $\mathrm{x}$ & $\mathrm{x}$ \\
\hline 72 & Di-galloyl hexoside & 6.22 & 203 & $483 / 301 / 169$ & & & $\mathrm{x}$ & \\
\hline 73 & Eucaglobulin & 6.23 & 276 & $497 / 345 / 327 / 313 / 183 / 169$ & $\mathrm{x}$ & $\mathrm{x}$ & & $\mathrm{x}$ \\
\hline 75 & Eucaglobulin & 6.25 & 270 & $497 / 345 / 327 / 313 / 183 / 169$ & $\mathrm{x}$ & $\mathrm{x}$ & & $\mathrm{x}$ \\
\hline 77 & Galloyl-HHDP-hexoside & 6.30 & 215 & $633 / 301$ & & & $\mathrm{x}$ & \\
\hline 79 & Castalagin/vescalagin isomer & 6.37 & $230,285 \mathrm{sh}$ & $933 / 915 / 889 / 871 / 631 / 613 / 587 / 569$ & $\mathrm{x}$ & $\mathrm{x}$ & $\mathrm{x}$ & $\mathrm{x}$ \\
\hline 81 & Castalagin/vescalagin isomer & 6.41 & 222 & $933 / 915 / 889 / 871 / 631 / 613 / 587 / 569$ & & $\mathrm{x}$ & $\mathrm{x}$ & $\mathrm{x}$ \\
\hline 82 & HHDP-NHTP-glucose-galloyl-di-HHDP-glucose (cocciferind2) & 6.46 & 224 & 933/915/633/631/301 & $\mathrm{x}$ & $\mathrm{x}$ & $\mathrm{x}$ & $\mathrm{x}$ \\
\hline 84 & Galloyl-bis-HHDP-glucose (potentilin/casuarictin isomer) & 6.51 & 221 & 935/917/873//783/633/301 & $\mathrm{x}$ & $\mathrm{x}$ & $\mathrm{x}$ & $\mathrm{x}$ \\
\hline 85 & Galloyl-bis-HHDP-glucose (potentilin/casuarictin isomer) & 6.55 & $225,280 \mathrm{sh}$ & 935/917/873//783/633/301 & & & $\mathrm{x}$ & \\
\hline 86 & Lambertianin C & 6.58 & 250 & $1401 / 1237 / 935 / 633303$ & $\mathrm{x}$ & $\mathrm{x}$ & $\mathrm{x}$ & $\mathrm{x}$ \\
\hline 88 & Methyl-4,6-digalloyl- $\beta$-D-glucopyranoside & 6.66 & 212 & $497 / 345 / 169$ & & & $\mathrm{x}$ & \\
\hline 92 & Trigalloyl-HHDP-glucose & 6.93 & $251 \mathrm{~nm}$ & $937 / 767 / 635 / 465 / 301$ & & & $\mathrm{x}$ & \\
\hline 93 & Ellagic acid-hexoside-pentoside & 6.99 & $253 / 361$ & $595 / 433 / 301$ & $\mathrm{x}$ & $\mathrm{x}$ & $\mathrm{x}$ & $\mathrm{x}$ \\
\hline 94 & Ellagic acid-hexoside-pentoside & 7.04 & $247 / 361$ & $595 / 433 / 301$ & & $\mathrm{x}$ & & \\
\hline 95 & Galloyl-bis-HHDP-glucose (potentilin/casuarictin isomer) & 7.06 & $253 / 357$ & 935/917/873//783/633/301 & & & $\mathrm{x}$ & \\
\hline 97 & Galloyl-bis-HHDP-glucose (potentilin/casuarictin isomer) & 7.13 & 221 & 935/917/873//783/633/301 & $\mathrm{x}$ & & & \\
\hline 98 & Castalagin/vescalagin isomer & 7.14 & $230,285 \mathrm{sh}$ & 933/915/889/871/631/613/587/569 & & & & $\mathrm{x}$ \\
\hline 99 & Ellagic acid pentoside & 7.23 & $254 / 361$ & $433 / 301$ & $\mathrm{x}$ & $\mathrm{x}$ & $\mathrm{x}$ & $\mathrm{x}$ \\
\hline 100 & Tetragalloyl-glucose & 7.27 & 227 & $787 / 635 / 617 / 573 / 465 / 403$ & & & $x$ & \\
\hline 102 & Ellagic acid hexoside & 7.34 & $254 / 362$ & $463 / 301$ & $\mathrm{x}$ & $\mathrm{x}$ & $\mathrm{x}$ & $\mathrm{x}$ \\
\hline 104 & Galloyl-bis-HHDP-glucose (potentilin/casuarictin isomer) & 7.41 & 218 & 935/917/873//783/633/301 & & $\mathrm{x}$ & & \\
\hline 106 & Galloyl-bis-HHDP-glucose (potentilin/casuarictin isomer) & 7.43 & 219 & 935/917/873//783/633/301 & $\mathrm{x}$ & & $\mathrm{x}$ & \\
\hline 108 & Ellagic acid ${ }^{a}$ & 7.50 & $255 / 365$ & 300.99 & $\mathrm{x}$ & $\mathrm{x}$ & $\mathrm{x}$ & $\mathrm{x}$ \\
\hline 110 & Castalagin/vescalagin isomer & 7.81 & $250 / 373$ & 933/915/889/871/631/613/587/569 & & & $\mathrm{x}$ & \\
\hline 111 & Pentagalloylglucoside & 8.04 & 280 & $939 / 769 / 617 / 465 / 313 / 169$ & & & $\mathrm{x}$ & \\
\hline 113 & Methyl galloyl-glucoside & 8.24 & $297 / 325$ & $345 / 183$ & & $\mathrm{x}$ & & \\
\hline 114 & Trigalloyl-HHDP-glucose & 8.26 & $259 / 360$ & $937 / 7767 / 301$ & & & $\mathrm{x}$ & \\
\hline 115 & Trigalloyl- $\beta$ - $D$-methyl glucoside & 8.35 & $263 / 356$ & $649 / 497 / 479 / 345$ & & & $\mathrm{x}$ & \\
\hline 118 & Di-galloyl hexoside & 8.54 & $261 / 374$ & $483 / 301$ & & & $\mathrm{x}$ & \\
\hline 127 & $3,3^{\prime}, 4^{\prime}$-O-trimethyl ellagic acid & 9.66 & 352 & $343 / 328$ & & $\mathrm{x}$ & & \\
\hline 128 & $3,3^{\prime}, 4^{\prime}$-O-trimethyl ellagic acid & 9.79 & 353 & $343 / 328$ & & $\mathrm{x}$ & & \\
\hline 129 & 3,4'-O-dimethyl ellagic acid & 10.55 & $249 / 359$ & $329 / 314 / 298 / 285$ & & & $\mathrm{x}$ & \\
\hline
\end{tabular}


Table 1. Cont.

\begin{tabular}{|c|c|c|c|c|c|c|c|c|}
\hline No & Compounds & Rt [min] & $\Delta[\mathrm{nm}]$ & MS/MS & $F \neq$ & $\mathbf{L}$ & $\mathbf{R}$ & $\mathbf{S}$ \\
\hline 130 & 3,4'-O-dimethyl ellagic acid & 11.11 & $247 / 362$ & $329 / 314 / 298 / 285$ & & & $\mathrm{x}$ & \\
\hline \multicolumn{9}{|c|}{ Sanguiin } \\
\hline 11 & Sanguiin H-6 & 2.74 & $234 / 320$ & $1870 / 1567 / 1265 / 933 / 631 / 301$ & $\mathrm{x}$ & $\mathrm{x}$ & & $\mathrm{x}$ \\
\hline 41 & Sanguiin $\mathrm{H}-4$ & 4.84 & $235 / 280 \mathrm{sh}$ & $633 / 300.99$ & $\mathrm{x}$ & & & \\
\hline 48 & Sanguiin H-10 isomer & 5.23 & 313 & 1567/1265/1103/933/301 & $\mathrm{x}$ & $\mathrm{x}$ & & $\mathrm{x}$ \\
\hline 65 & Sanguiin H-1 & 5.99 & $230 / 280 \mathrm{sh}$ & $785 / 633 / 465 / 301$ & $\mathrm{x}$ & & & \\
\hline 69 & Sanguiin H-1 & 6.13 & $254 / 371$ & $785 / 633 / 465 / 301$ & & $\mathrm{x}$ & $\mathrm{x}$ & $\mathrm{x}$ \\
\hline 89 & Sanguiin H-6 & 6.75 & 236 & 1870/1567/1265/933/631/301 & $\mathrm{x}$ & $\mathrm{x}$ & $\mathrm{x}$ & $\mathrm{x}$ \\
\hline 96 & Sanguiin H-1 & 7.12 & 221 & $785 / 633 / 465 / 301$ & & $\mathrm{x}$ & $\mathrm{x}$ & \\
\hline 119 & Sanguiin H-7 & 8.59 & $261 / 361$ & $801 / 649 / 301$ & & & $\mathrm{x}$ & \\
\hline 122 & Sanguiin H-7 isomer & 9.05 & 334 & $801 / 649 / 301$ & $\mathrm{x}$ & $\mathrm{x}$ & & $\mathrm{x}$ \\
\hline \multicolumn{9}{|c|}{ Sanguisorbic acids } \\
\hline 9 & Sanguisorbic acid dilactone & 2.13 & 272 & $469 / 314 / 301 / 286$ & & $\mathrm{x}$ & $\mathrm{x}$ & \\
\hline 12 & Sanguisorbic acid dilactone & 2.89 & 275 & $469 / 314 / 301 / 286$ & & & $\mathrm{x}$ & \\
\hline 52 & Sanguisorbic acid glucoside & 5.47 & 325 & $667 / 285$ & & $\mathrm{x}$ & & $\mathrm{x}$ \\
\hline \multicolumn{9}{|c|}{ Phenolic acids } \\
\hline 16 & Caffeoylquinic acid ${ }^{a}$ & 3.50 & 322 & $353 / 191 / 179 / 161$ & $\mathrm{x}$ & $\mathrm{x}$ & & \\
\hline 19 & 3-O-caffeoylquinic acid $^{\text {a }}$ & 3.72 & 323 & $353 / 191 / 179 / 135$ & $\mathrm{x}$ & $\mathrm{x}$ & & $\mathrm{x}$ \\
\hline 32 & 3-O-p-coumaroylquinic acid ${ }^{\mathrm{a}}$ & 4.50 & 311 & 337163 & $\mathrm{x}$ & $\mathrm{x}$ & & \\
\hline 33 & Rosmarinic acid & 4.54 & 325 & 359/191/179/173/163/152 & & $\mathrm{x}$ & & $\mathrm{x}$ \\
\hline 42 & 5-O-caffeoylquinic acid ${ }^{a}$ & 4.87 & 324 & $353 / 191 / 179$ & $\mathrm{x}$ & $\mathrm{x}$ & & $\mathrm{x}$ \\
\hline 78 & 3-O-feruloylquinic acid ${ }^{\text {a }}$ & 6.36 & 324 & $367 / 193 / 191$ & $x$ & $x$ & & $\mathrm{x}$ \\
\hline 116 & Disuccinoyl-caffeoylquinic acids & 8.41 & 326 & $\begin{array}{l}553 / 537 / 515 / 375 / 353 / 191 / \\
179 / 173\end{array}$ & $\mathrm{x}$ & $x$ & & $\mathrm{x}$ \\
\hline 120 & 3,5-dicaffeoylquinic acid & 8.83 & 326 & $515 / 353 / 191 / 179 / 173$ & $\mathrm{x}$ & $\mathrm{x}$ & & $\mathrm{x}$ \\
\hline 121 & 3,5-dicaffeoylquinic acid & 8.91 & 326 & $515 / 353 / 191 / 179 / 173$ & $\mathrm{x}$ & $\mathrm{x}$ & & $\mathrm{x}$ \\
\hline 123 & Caffeoyl dihexoside & 9.27 & 325 & $503 / 341 / 179$ & $\mathrm{x}$ & $\mathrm{x}$ & & $\mathrm{x}$ \\
\hline 124 & Caffeoyl dihexoside & 9.36 & 313 & $503 / 341 / 179$ & $\mathrm{x}$ & $\mathrm{x}$ & & $\mathrm{x}$ \\
\hline 125 & Caffeoyl dihexoside & 9.50 & 326 & $503 / 341 / 179$ & $\mathrm{x}$ & $\mathrm{x}$ & & $\mathrm{x}$ \\
\hline 126 & Caffeoyl dihexoside & 9.64 & 326 & $503 / 341 / 179$ & & & $\mathrm{x}$ & \\
\hline \multicolumn{9}{|c|}{ Anthocyanins } \\
\hline 21 & Cyanidin 3,5-O-diglucoside & 3.91 & 520 & $611 / 449 / 287$ & $\mathrm{x}$ & & & \\
\hline 46 & Cyanidin 3-O-glucoside ${ }^{a}$ & 5.05 & 516 & $449 / 287$ & $\mathrm{x}$ & & & \\
\hline 76 & Cyanidin 3-O-malonylglucoside & 6.28 & 517 & $535 / 287$ & $\mathrm{x}$ & & & \\
\hline
\end{tabular}


Table 1. Cont.

\begin{tabular}{|c|c|c|c|c|c|c|c|c|}
\hline No & Compounds & Rt [min] & $\Delta[\mathrm{nm}]$ & MS/MS & $\mathbf{F} \ddagger$ & $\mathbf{L}$ & $\mathbf{R}$ & $\mathrm{S}$ \\
\hline 87 & Cyanidin 3-O-rutinoside & 6.60 & 518 & $595 / 449 / 287$ & $\mathrm{x}$ & & & \\
\hline 90 & Cyanidin 3-O-malonylglucoside & 6.77 & 517 & $535 / 287$ & $\mathrm{x}$ & & & \\
\hline 91 & Cyanidin 3-(6-O-acetyl)-glucoside & 6.91 & 518 & $491 / 317 / 303 / 287$ & $\mathrm{x}$ & & & \\
\hline \multicolumn{9}{|c|}{ Catechins and Proanthocyanidins } \\
\hline 31 & $(+)$-Catechin ${ }^{a}$ & 4.43 & 281 & 289 & $\mathrm{x}$ & $x$ & $\mathrm{x}$ & $\mathrm{x}$ \\
\hline 36 & B-type (epi)catechin dimmer a & 4.58 & 276 & $577 / 289$ & $\mathrm{x}$ & $\mathrm{x}$ & & $\mathrm{x}$ \\
\hline 38 & B-type (epi)catechin dimmer a & 4.67 & 279 & $577 / 289$ & & $\mathrm{x}$ & $\mathrm{x}$ & \\
\hline 39 & B-type (epi)catechin dimmer a & 4.69 & 279 & $577 / 289$ & $\mathrm{x}$ & $\mathrm{x}$ & & $\mathrm{x}$ \\
\hline 40 & (-)-Epicatechin ${ }^{\text {a }}$ & 4.83 & 279 & 289 & $\mathrm{x}$ & $\mathrm{x}$ & $\mathrm{x}$ & $\mathrm{x}$ \\
\hline 43 & B-type (epi)catechin trimmer & 4.94 & 280 & $865 / 577 / 289$ & & & & $\mathrm{x}$ \\
\hline 57 & B-type (epi)catechin tetramer & 5.63 & 278 & $1153 / 863 / 577 / 289$ & $\mathrm{x}$ & $\mathrm{x}$ & $\mathrm{x}$ & $\mathrm{x}$ \\
\hline 59 & B-type (epi)catechin tetramer & 5.70 & 278 & $1153 / 863 / 577 / 290$ & $\mathrm{x}$ & $\mathrm{x}$ & $\mathrm{x}$ & $\mathrm{x}$ \\
\hline 63 & B-type (epi)catechin dimmer a & 5.90 & 274 & $577 / 289$ & $\mathrm{x}$ & $\mathrm{x}$ & $\mathrm{x}$ & $\mathrm{x}$ \\
\hline 74 & A-type procyanidins tetramer & 6.23 & $221 / 273$ & $1153 / 865 / 575 /$ & & & $\mathrm{x}$ & \\
\hline 80 & B-type (epi)catechin tetramer & 6.41 & 278 & $1153 / 863 / 577 / 289$ & & & $\mathrm{x}$ & \\
\hline 83 & B-type (epi)catechin dimmer ${ }^{a}$ & 6.46 & 276 & $577 / 289$ & & & $\mathrm{x}$ & \\
\hline \multicolumn{9}{|c|}{ Flavonols } \\
\hline 45 & Quercetin 3-O-glucoside a & 5.03 & 358 & $463 / 301$ & & $\mathrm{x}$ & & $\mathrm{x}$ \\
\hline 61 & Kaempferol-di-O-rhamnoside & 5.80 & 350 & $577 / 431 / 285$ & $\mathrm{x}$ & $\mathrm{x}$ & & $\mathrm{x}$ \\
\hline 101 & Quercetin 3-O-(6"'-galloylglucose) & 7.30 & 224 & $615 / 463 / 300.027$ & & $\mathrm{x}$ & & \\
\hline 103 & Taxifolin 7-O- $\beta$-D-glucopyranoside & 7.35 & 229 & $465 / 285$ & & & $\mathrm{x}$ & \\
\hline 105 & Quercetin-glucoside-rhamnoside-rhamnoside & 7.41 & $254 / 337$ & $755 / 609 / 463 / 300.027$ & $\mathrm{x}$ & $\mathrm{x}$ & & $\mathrm{x}$ \\
\hline 107 & Quercetin rhamnosyl-rutinoside & 7.47 & 368 & $755 / 609 / 301$ & $\mathrm{x}$ & $\mathrm{x}$ & & $\mathrm{x}$ \\
\hline 109 & Quercetin 3-O-glucuronide & 7.68 & $255 / 353$ & $477 / 300.027$ & $\mathrm{x}$ & $\mathrm{x}$ & $\mathrm{x}$ & $\mathrm{x}$ \\
\hline 112 & Quercetin 3-O-acetyl glucoside & 8.15 & 355 & $505 / 300.027$ & $\mathrm{x}$ & $\mathrm{x}$ & & $\mathrm{x}$ \\
\hline 117 & Kaempferol 3-O-glucuronide & 8.49 & 347 & $461 / 285$ & & $x$ & & $\mathrm{x}$ \\
\hline \multicolumn{9}{|c|}{ Triterpenoid saponins } \\
\hline 22 & Sanguisorbigenin & 3.98 & $223 / 271$ & $453 / 345 / 183 / 169$ & $\mathrm{x}$ & $\mathrm{x}$ & & $x$ \\
\hline
\end{tabular}




In contrast, sanguisorbic acids, belonging to the hydrolyzed tannins, also have been previously defined for these plants by Zhu et al. [2] as sanguisorbic acid dilactone $(9,12 ; \mathrm{m} / \mathrm{z} 469)$ and sanguisorbic acid glucoside $(52 ; m / z$ 667). These compounds were determined only in the leaves, stalks, and roots of $S$. officinalis L. Moreover, 1 sanguisorbigenin, belonging to the triterpenoid saponins, was detected during identification P. granatum [12].

UV detection at the characteristic absorption maximum between 310 and $330 \mathrm{~nm}$ [19] showed the presence of 13 hydroxycinnamic acids in flowers, leaves, and stalks in the case of which the esterification of their quinic acid residue occurs at positions 3, 4, and 5, but not at position 1 [19]. Of these, 5 were identified early in $S$. officinalis as caffeoylquinic acid (16, $\mathrm{m} / \mathrm{z} 353), 3-O$-caffeoylquinic acid (19; $\mathrm{m} / \mathrm{z} 353)$, 3-O-p-coumaroylquinic acid (32; $m / z$ 337), 5-O-caffeoylquinic acid (42; $m / z 353)$, and 3-O-feruloylquinic acid $(78 ; m / z$ 367) [12]. However, 4 more were previously identified in other botanical sources like Eryngium alpinum L. and Chrysanthemum as rosmarinic acid (33; $\mathrm{m} / \mathrm{z} 359)$, disuccinoyl-caffeoylquinic acids (116; $\mathrm{m} / \mathrm{z} 553)$, and 3,5-dicaffeoylquinic $(120,121 ; \mathrm{m} / \mathrm{z} 515)$, however, for the first time in $\mathrm{S}$. officinalis L., compounds No. 123-125 were tentatively identified as caffeoyl dihexoside based on the highest peak at $m / z 505$ and its fragmentation yielding peaks at $m / z 341$ and 179 due to the loss of 2 hexose residues $(162+162 \mathrm{Da})$. What is more, these compounds were also described for the first time ever in morphological parts of $S$. officinalis $\mathrm{L}$.

Anthocyanins are natural plant pigments occurring in the plant kingdom. They were identified in the positive ion mode because they bear a positive charge and easily donate protons to free radicals under ESI conditions. In turn, their detection was carried out at the typical absorption maximum between 440 and $540 \mathrm{~nm}[10,20]$. Among the tentatively identified 6 anthocyanins, that were detected only in the flowers, only 4 were earlier determined in S. officinalis L. as cyanidin 3,5-diglucoside (21; $m / z 611)$, cyanidin 3-O-glucoside (46; $m / z 449)$, and cyanidin 3 -malonylglucoside $(76,90 ; \mathrm{m} / \mathrm{z} 535)$ [12]. The other 2 compounds were described based on previous information about fragmentation of pomegranate and grape berry skin $[13,21]$ as cyanidin $3-O$-rutinoside $(87 ; \mathrm{m} / \mathrm{z} 595)$ and cyanidin 3-(6-O-acetyl)-glucoside (91; $m / z$ 491).

Flavan-3-ols occur as monomers, oligomers, and polymers formed by linking to (epi)catechin monomers via interflavonoid bonds (C-C) [22]. Their fragmentation proceeds through the loss of a (epi)catechin unit with a molecular weight of $289 \mathrm{Da}$. The identified proanthocyanins occurred as catechin dimers, trimers, and tetramers and were identified as A and B procyanidins [22]. These 11 compounds were characterized based on available standards and the latest research works addressing $S$. officinalis $\mathrm{L}$ as (+)-catechin and (-)-epicatechin (31, 40; $\mathrm{m} / \mathrm{z} 289)$, B-type (epi)catechin dimmer $(36,38,39,63,83 ; \mathrm{m} / \mathrm{z} 577)$, B-type (epi)catechin trimmer (43; $\mathrm{m} / \mathrm{z}$ 865), and B-type (epi)catechin tetramer $(57,59,80 ; m / z$ 1153) [2,3]. In turn, compound No. 74 was tentatively identified as a A-type (epi)catechin tetramer at $m / z 1153$ and the base ion at $m / z$ 289. Although it was earlier detected in black soybean [23], it was described in S. officinalis L. for the first time ever.

Flavonols were identified as derivatives of taxifolin, kaempferol, and quercetin based on the base fragments at $m / z 300,285$, and 301. UV detection of flavonols revealed characteristic absorption maximum between 315 and $359 \mathrm{~nm}$, and some of the identified compounds had additional peaks between 207 and $280 \mathrm{~nm}$ [24]. Besides, derivatives of these compounds are usually detected at positions C-7 and/or C-3. Fragmentation of the primary ions resulted in losses of hexose (162 Da), pentose $(146 \mathrm{Da})$, and deoxyhexose (308 Da) [24]. Of the 9 flavonols initially suggested for $S$. officinalis L., only 6 have previously been described for this species as quercetin-3-O-glucoside (45; 463), quercetin-3-O-(6" -galloylglucose) $(101 ; m / z 615)$, taxifolin-7-O- $\beta$-D-glucopyranoside (103; $m / z$ 465), quercetin-3-O-glucuronide (109; $\mathrm{m} / \mathrm{z} 477)$, quercetin-3-O-acetyl glucoside (112; $\mathrm{m} / \mathrm{z} 505)$, and kaempferol-3-O-glucuronide $(117 ; m / z 461)[2,3,12]$. In turn, 3 compounds have not been previously described according to the available literature. Compound No. 61 was tentatively identified as kaempferol-di-O-rhamnoside based on the primary peak at $\mathrm{m} / \mathrm{z} 577$ and fragmentation peaks at $\mathrm{m} / \mathrm{z}$ 431 and 285 due to the loss of two rhamnoside residues (146 + $146 \mathrm{Da})$. Another compound (103) was tentatively described as quercetin-glucoside-dirhamnoside based on the primary peak at $\mathrm{m} / \mathrm{z} 755$ and 
fragmentation peaks at $m / z 609,463$, and 301 due to the loss of two rhamnose residues and one glycosyl residue. Finally, compound No. 107 was tentatively presented as quercetin rhamnosyl-rutinoside based on the primary peak at $m / z 755$ and fragmentation peaks at $m / z 609$ and 301 .

\subsection{Quantification of Polyphenolic Compounds}

The content of polyphenols in the analyzed morphological parts of S. officinalis L. is shown in Table 2. The highest content of bioactive compounds was determined in the flowers, it reached $14,444.97 \mathrm{mg} / 100 \mathrm{~g}$ d.b. and was 1.5, 1.7, and 3.2 times higher than in the leaves, roots, and stalks, respectively. In turn, the content of polyphenols in the leaves + stalks of Sanguisorba minor Scop. was comparable to the content of these compounds in S. officinalis L., while the roots of S. minor Scop. were 4 times more abundant in the studied compounds than the roots of $S$. officinalis L. [3]. In turn, the sum of polyphenols analysed in the roots of the same species from Korea was 2 times lower than in the roots of plants grown in Poland. However, the extract from S. officinalis L. cultivated in China contained $3150 \mathrm{mg}$ GAE/100 g dry weight polyphenols, which was 4.9, 3.2, 2.8, and 1.5 times lower compared to the flowers, leaves, roots, and stalks of the same species growing in Poland. The content of polyphenols in the leaves of green and white tea was 67.21 and $40.94 \mathrm{mg} / \mathrm{g}$ d.b. and was 1.5 and 2.4 times lower than in the leaves of the studied species, respectively [25]. Total content of polyphenols analyzed in the flowers, leaves, roots, and stalks of S. officinalis L. was 8.2, 8.4, 7.8, and 8.4 times higher, respectively, compared to edible flowers of Allium schoenoprasum (Liliaceae), Salvia pratensis (Lamiaceae), Sambucus nigra (Caprifoliaceae), Taraxacum officinale [26]. However, according to Zeng et al. [27] the contents of bioactive compounds in the flowers of green and black tea of Camellia sinensis were 2.4 and 5.4 times lower, respectively, compared to the flowers of S. officinalis L. Moreover, the content of bioactive compounds in the flowers and the leaves of Punica granatum L. was 2.2 and 6.7 times lower, respectively, than in the same morphological parts of S. officinalis L. [28]. In addition, the content of compounds tested in the leaves and the stalks of Fallopia japonica was 1.7 and 2.3 times lower, respectively, while their content in the roots of $F$. japonica was similar to $S$. officinalis L. [9]. The differences in the contents of polyphenolic compounds among individual species can be affected by various factors, such as the place of cultivation, climate, environmental conditions, and also the method of extraction and analysis [29]. Thus, the tested material is characterized by a high content of compounds exhibiting a number of biological properties and can be used to compose not only nutraceuticals in the pharmaceutical industry but also to produce functional food.

The profile and content of phenols present in various morphological parts of S. officinalis L. were quite diverse and strongly dependent on the morphological part tested. The flowers were dominated by hydrolyzed tannins $(66.4 \%$ in all phenols $)>$ flavan-3-ols $(13.1 \%)>$ phenolic acids $(9.9 \%)>$ flavonols $(5 \%)>$ anthocyanins $(3.8 \%)>$ triterpenoids $(1.8 \%)$. In turn, in the leaves were dominated by hydrolyzed tannins $(49.3 \%)>$ phenolic acids $(20.5 \%)>$ flavonols $(19.8 \%)>$ flavan-3-ols $(7.4 \%)>$ triterpenoids $(3 \%)$. However, in the roots, hydrolyzed tannins were also the dominant class $(62.1 \%)>$ flavan-3-ols $(37.3 \%)>$ phenolic acids and flavonols $(<0.5 \%)$, whereas the stalks were dominated by hydrolyzed tannins $(43.3 \%)$ $>$ flavan-3-ols $(26.2 \%)>$ flavonols $(17.1 \%)>$ phenolic acids $(7.8 \%)>$ triterpenes $(5.5 \%)$. The analysis of phenols profile revealed flavonols to be the major group in leaf + stalks, whereas hydrolyzed tannins to be the major group in the roots of S. minor [3], similarly to the roots of S. officinalis L. and to the results presented in the work of Kim et al. [1]. 
Table 2. Content of polyphenolic compounds in Sanguisorba officinalis [mg/100 g d.w.].

\begin{tabular}{|c|c|c|c|c|c|}
\hline & Compounds & Flower & Leaves & Roots & Stalk \\
\hline & \multicolumn{5}{|l|}{ Hydrolyzable tannins } \\
\hline 1 & 2,3-HHDP- $(\alpha / \beta)$-glucose & nd $\ddagger$ & nd & $12.33 \pm 0.25 \mathrm{a}^{+}$ & nd \\
\hline 2 & HHDP-hex(2,3-(S)-Hexahydroxydiphenoyl-D-glucose) & $141.89 \pm 2.84 a$ & $102.71 \pm 2.05 b$ & $13.28 \pm 0.27 c$ & $11.49 \pm 0.23 c$ \\
\hline 3 & HHDP-hexoside(1-galloyl-2,3-hexahydroxydiphenoyl- $\alpha$-glucose) & nd & $14.36 \pm 0.29 a$ & nd & nd \\
\hline 4 & HHDP-hex(2,3-(S)-Hexahydroxydiphenoyl-D-glucose) & $161.00 \pm 3.22 \mathrm{a}$ & $63.35 \pm 1.27 \mathrm{~b}$ & $40.73 \pm 0.81 c$ & $12.49 \pm 0.25 \mathrm{~d}$ \\
\hline 5 & Galloyl-hexoside( $\beta$-glucogallin) & nd & nd & $92.13 \pm 1.84 \mathrm{a}$ & nd \\
\hline 6 & Galloyl-pentoside & nd & nd & $38.51 \pm 0.77 a$ & nd \\
\hline 7 & Galloyl-hexoside & nd & nd & $20.66 \pm 0.41 \mathrm{a}$ & nd \\
\hline 8 & Galloyl-hexoside & nd & $13.89 \pm 0.28 \mathrm{a}$ & nd & nd \\
\hline 10 & Galloyl-hexoside & nd & $5.18 \pm 0.10 b$ & nd & $9.52 \pm 0.19 a$ \\
\hline 13 & Galloyl-hexoside & nd & $4.41 \pm 0.09 a$ & nd & nd \\
\hline 14 & Di-galloyl-HHDP-glucose (tellimagrandin I) & $5.57 \pm 0.11 \mathrm{a}$ & $6.34 \pm 0.13 a$ & nd & $1.35 \pm 0.03 b$ \\
\hline 15 & Di-HHDP-glucose (pedunculagin isomer) & $100.66 \pm 2.01 b$ & $24.25 \pm 0.49 c$ & $136.03 \pm 2.72 a$ & $15.78 \pm 0.32 \mathrm{~d}$ \\
\hline 17 & Methyl-6-O-galloyl- $\beta$-D-glucopyranoside & nd & nd & $234.27 \pm 4.69 \mathrm{a}$ & $7.20 \pm 0.14 b$ \\
\hline 18 & Pedunculagin 1 & $2.55 \pm 0.05 a$ & nd & nd & nd \\
\hline 20 & Di-HHDP-glucose (pedunculagin isomer) & $2.23 \pm 0.04 a$ & nd & nd & nd \\
\hline 23 & Pedunculagin1 & $9.08 \pm 0.18 a$ & nd & nd & nd \\
\hline 26 & Di-HHDP-glucose (pedunculagin isomer) & nd & $17.21 \pm 0.34 \mathrm{a}$ & nd & nd \\
\hline 27 & Di-HHDP-glucose (pedunculagin isomer) & $97.32 \pm 1.95 \mathrm{a}$ & nd & $42.58 \pm 0.85 b$ & nd \\
\hline 28 & $\beta$-1-O-galloyl-2,3-(S)-HHDP-D-glucose & $513.20 \pm 10.26 a$ & $433.89 \pm 8.68 b$ & nd & $83.52 \pm 1.67 c$ \\
\hline 29 & Pedunculagin1 & nd & nd & $24.37 \pm 0.49 \mathrm{a}$ & nd \\
\hline 30 & Di-HHDP-glucose (pedunculagin isomer) & $9.66 \pm 0.19 b$ & $11.96 \pm 0.24 a$ & nd & $2.01 \pm 0.04 c$ \\
\hline 34 & Di-HHDP-glucoside & nd & nd & $19.51 \pm 0.39 a$ & 0 \\
\hline 35 & Methylellagic acid-pentose & $26.83 \pm 0.54 a$ & $5.45 \pm 0.11 c$ & nd & $8.17 \pm 0.16 b$ \\
\hline 37 & Di-galloyl-glucoside & nd & nd & $53.85 \pm 1.08 \mathrm{a}$ & nd \\
\hline 44 & Galloyl-HHDP-glucose & $165.31 \pm 3.31 \mathrm{a}$ & $8.65 \pm 0.17 c$ & $145.15 \pm 2.90 b$ & $5.25 \pm 0.11 \mathrm{~d}$ \\
\hline 47 & HHDP-NHTP-glucose (castalagin/vescalagin) & $87.29 \pm 1.75 b$ & $100.59 \pm 2.01 \mathrm{a}$ & $41.30 \pm 0.83 c$ & $23.36 \pm 0.47 \mathrm{~d}$ \\
\hline 49 & HHDP-glucose & $97.26 \pm 1.95 a$ & $45.3 \pm 0.91 b$ & $11.32 \pm 0.23 c$ & $11.44 \pm 0.23 c$ \\
\hline 50 & Methyl-4,6-digalloyl- $\beta$-D-glucopyranoside & $7.94 \pm 0.16 b$ & $1.06 \pm 0.02 \mathrm{c}$ & $17.12 \pm 0.34 a$ & $0.58 \pm 0.01 \mathrm{~d}$ \\
\hline
\end{tabular}


Table 2. Cont.

\begin{tabular}{|c|c|c|c|c|c|}
\hline & Compounds & Flower & Leaves & Roots & Stalk \\
\hline 51 & HHDP-NHTP-glucose (castalagin/vescalagin) & nd & nd & $24.08 \pm 0.48 a$ & nd \\
\hline 53 & HHDP-galloyl-glucose & $43.97 \pm 0.88 \mathrm{a}$ & nd & nd & nd \\
\hline 54 & Galloylglucoronide & nd & nd & $93.44 \pm 1.87 \mathrm{a}$ & nd \\
\hline 56 & Di-galloyl-HHDP-glucose (tellimagrandin I) & $85.77 \pm 1.72 \mathrm{a}$ & $35.62 \pm 0.71 b$ & nd & nd \\
\hline 58 & Castalagin/vescalagin isomer & $37.38 \pm 0.75 a$ & $70.71 \pm 1.41 b$ & nd & nd \\
\hline 60 & Ellagic acid-pentoside & $9.31 \pm 0.19 b$ & $13.70 \pm 0.27 a$ & nd & $3.96 \pm 0.08 c$ \\
\hline 62 & Methyl-4,6-digalloyl- $\beta$-D-glucopyranoside & $256.75 \pm 5.14 a$ & $104.29 \pm 2.09 b$ & $254.04 \pm 5.08 \mathrm{a}$ & $71.93 \pm 1.44 \mathrm{c}$ \\
\hline 66 & Di-galloyl-HHDP-glucose (tellimagrandin I) & nd & nd & $13.52 \pm 0.27 \mathrm{a}$ & nd \\
\hline 67 & Ellagic acid hexoside & $5.76 \pm 0.12 b$ & $7.16 \pm 0.14 a$ & $4.05 \pm 0.08 b$ & $2.61 \pm 0.05 c$ \\
\hline 68 & Ellagic acid hexoside & nd & nd & nd & $4.53 \pm 0.09 a$ \\
\hline 70 & Castalagin/vescalagin isomer & nd & nd & $68.46 \pm 1.37 \mathrm{a}$ & nd \\
\hline 71 & Methyl-4,6-digalloyl- $\beta$-D-glucopyranoside & nd & $1.80 \pm 0.04 a$ & $1.70 \pm 0.03 \mathrm{a}$ & $0.58 \pm 0.01 b$ \\
\hline 72 & Di-galloyl hexoside & nd & nd & $43.6 \pm 0.87 a$ & nd \\
\hline 73 & Eucaglobulin & $51.84 \pm 1.04 \mathrm{~b}$ & $102.83 \pm 2.06 a$ & nd & $16.79 \pm 0.34 c$ \\
\hline 75 & Eucaglobulin & $71.19 \pm 1.42 \mathrm{a}$ & $71.72 \pm 1.43 a$ & nd & $22.59 \pm 0.45 b$ \\
\hline 77 & Galloyl-HHDP-hexoside & nd & nd & $106.23 \pm 2.12 a$ & nd \\
\hline 81 & Castalagin/vescalagin isomer & nd & $92.82 \pm 1.86 a$ & $67.43 \pm 1.35 b$ & $13.19 \pm 0.26 c$ \\
\hline 82 & HHDP-NHTP-glucose-galloyl-di-HHDP-glucose (cocciferind2) & $87.01 \pm 1.74 b$ & $41.02 \pm 0.82 c$ & $155.76 \pm 3.12 \mathrm{a}$ & $13.57 \pm 0.27 \mathrm{~d}$ \\
\hline 84 & Galloyl-bis-HHDP-glucose (potentilin/casuarictin isomer) & $38.45 \pm 0.77 \mathrm{~b}$ & $132.33 \pm 2.65 a$ & $32.87 \pm 0.66 c$ & $30.56 \pm 0.61 c$ \\
\hline 85 & Galloyl-bis-HHDP-glucose (potentilin/casuarictin isomer) & nd & nd & $52.26 \pm 1.05 a$ & nd \\
\hline 86 & Lambertianin C & $3029.28 \pm 60.59 a$ & $2232.84 \pm 44.66 b$ & $898.98 \pm 17.98 \mathrm{~d}$ & $1236.77 \pm 24.74 \mathrm{c}$ \\
\hline 88 & Methyl-4,6-digalloyl- $\beta$-D-glucopyranoside & nd & nd & $4.82 \pm 0.1 \mathrm{a}$ & nd \\
\hline 92 & Trigalloyl-HHDP-glucose & nd & nd & $86.34 \pm 1.73 a$ & nd \\
\hline 93 & Ellagic acid-hexoside-pentoside & $33.54 \pm 0.67 a$ & $32.53 \pm 0.65 a$ & $32.80 \pm 0.66 a$ & $7.09 \pm 0.14 b$ \\
\hline 94 & Ellagic acid-hexoside-pentoside & nd & $51.34 \pm 1.03 a$ & nd & nd \\
\hline 95 & Galloyl-bis-HHDP-glucose (potentilin/casuarictin isomer) & nd & nd & $12.48 \pm 0.25 a$ & nd \\
\hline 97 & Galloyl-bis-HHDP-glucose (potentilin/casuarictin isomer) & $30.53 \pm 0.61 \mathrm{a}$ & nd & nd & nd \\
\hline 98 & Castalagin/vescalagin isomer & nd & nd & nd & $43.38 \pm 0.87 a$ \\
\hline 99 & Ellagic acid pentoside & $14.50 \pm 0.29 b$ & $15.22 \pm 0.3 b$ & $18.07 \pm 0.36 \mathrm{a}$ & $3.47 \pm 0.07 c$ \\
\hline 100 & Tetragalloyl-glucose & nd & nd & $328.94 \pm 6.58 \mathrm{a}$ & nd \\
\hline 102 & Ellagic acid hexoside1 & $1.14 \pm 0.02 \mathrm{a}$ & $0.33 \pm 0.01 c$ & $0.61 \pm 0.01 b$ & $0.36 \pm 0.01 c$ \\
\hline
\end{tabular}


Table 2. Cont

\begin{tabular}{|c|c|c|c|c|c|}
\hline & Compounds & Flower & Leaves & Roots & Stalk \\
\hline 104 & Galloyl-bis-HHDP-glucose (potentilin/casuarictin isomer) & nd & $56.41 \pm 1.13 a$ & nd & nd \\
\hline 106 & Galloyl-bis-HHDP-glucose (potentilin/casuarictin isomer) & $202.46 \pm 4.05 a$ & nd & $147.72 \pm 2.95 b$ & nd \\
\hline 108 & Ellagic acid & $17.69 \pm 0.35 c$ & $26.90 \pm 0.54 a$ & $13.49 \pm 0.27 \mathrm{~b}$ & $5.20 \pm 0.10 \mathrm{~d}$ \\
\hline 111 & Pentagalloylglucoside & nd & nd & $36.57 \pm 0.73 a$ & nd \\
\hline 113 & Methyl galloyl-glucoside & nd & $13.75 \pm 0.28 \mathrm{a}$ & nd & nd \\
\hline 114 & Trigalloyl-HHDP- glucose & nd & nd & $0.71 \pm 0.01 \mathrm{a}$ & nd \\
\hline 115 & Trigalloyl- $\beta-D$-methyl glucoside & nd & nd & $35.65 \pm 0.71 \mathrm{a}$ & nd \\
\hline 127 & $3,3^{\prime}, 4^{\prime}-O$-trimethyl ellagic acid & nd & $31.41 \pm 0.63 a$ & nd & nd \\
\hline 128 & $3,3^{\prime}, 4^{\prime}-O$-trimethyl ellagic acid & nd & $1.47 \pm 0.03 a$ & nd & nd \\
\hline 129 & 3,4'-O-dimethyl ellagic acid & nd & nd & $49.05 \pm 0.98 \mathrm{a}$ & nd \\
\hline \multirow[t]{3}{*}{130} & 3,4'-O-dimethyl ellagic acid & nd & nd & $251.11 \pm 5.02 \mathrm{a}$ & nd \\
\hline & SUM & $5497.24 \pm 109.94 a$ & $4090.71 \pm 81.81 b$ & $3865.92 \pm 77.32 c$ & $1686.73 \pm 33.73 d$ \\
\hline & Sanguiin & & & & \\
\hline 11 & Sanguiin H-6 & $2.57 \pm 0.05 b$ & $10.13 \pm 0.20 \mathrm{a}$ & nd & $1.22 \pm 0.02 c$ \\
\hline 41 & Sanguiin H-4 & $352.14 \pm 7.04 a$ & nd & nd & nd \\
\hline 65 & Sanguiin $\mathrm{H}-1$ & $43.36 \pm 0.87$ & nd & nd & nd \\
\hline 69 & Sanguiin H-1 & nd & $1.01 \pm 0.02 b$ & $2.95 \pm 0.06 a$ & $0.15 \pm 0.01 c$ \\
\hline 89 & Sanguiin H-6 & $3566.15 \pm 71.32 \mathrm{a}$ & $621.04 \pm 12.42 \mathrm{~d}$ & $763.91 \pm 15.28 c$ & $289.86 \pm 5.80 \mathrm{~b}$ \\
\hline 96 & Sanguiin H-1 & nd & $61.95 \pm 1.24 b$ & $730.22 \pm 14.60 \mathrm{a}$ & nd \\
\hline 119 & Sanguiin H-7 & nd & nd & $4.42 \pm 0.09 \mathrm{a}$ & nd \\
\hline \multirow[t]{3}{*}{122} & Sanguiin H-7 isomer & $1.89 \pm 0.04 a$ & $2.24 \pm 0.04 a$ & nd & $0.98 \pm 0.02 b$ \\
\hline & SUM & $4097.03 \pm 81.94 a$ & $701.7 \pm 14.03 c$ & $1501.5 \pm 30.03 b$ & $296.35 \pm 5.93 d$ \\
\hline & Sanguisorbic acids & & & & \\
\hline 9 & Sanguisorbic acid dilactone & nd & $6.61 \pm 0.13 d$ & $10.95 \pm 0.22 \mathrm{a}$ & nd \\
\hline 12 & Sanguisorbic acid dilactone & nd & nd & $15.44 \pm 0.31 \mathrm{a}$ & nd \\
\hline \multirow[t]{3}{*}{52} & Sanguisorbic acid glucoside & nd & $109.18 \pm 2.18 \mathrm{a}$ & nd & $13.43 \pm 0.27 \mathrm{~b}$ \\
\hline & SUM & nd & $115.79 \pm 2.32 \mathrm{a}$ & $26.39 \pm 0.53 b$ & $13.43 \pm 0.27 \mathrm{c}$ \\
\hline & Phenolic acids & & & & \\
\hline 16 & Caffeoylquinic acid & $23.07 \pm 0.46 b$ & $47.52 \pm 0.95 a$ & nd & nd \\
\hline
\end{tabular}


Table 2. Cont

\begin{tabular}{|c|c|c|c|c|c|}
\hline & Compounds & Flower & Leaves & Roots & Stalk \\
\hline 19 & Caffeoylquinic acid & $539.00 \pm 10.78 b$ & $1363.67 \pm 27.27 a$ & nd & $182.92 \pm 3.66 c$ \\
\hline 32 & 3-p-Coumaroylquinic acid & $87.17 \pm 1.74 \mathrm{a}$ & $42.55 \pm 0.85 b$ & nd & nd \\
\hline 33 & Rosmarinic acid & nd & $8.39 \pm 0.17 a$ & nd & $2.98 \pm 0.06 b$ \\
\hline 78 & 3-Feruloylquinic acid & $11.46 \pm 0.23 a$ & $4.95 \pm 0.10 b$ & nd & $3.17 \pm 0.06 c$ \\
\hline 116 & Disuccinoyl-caffeoylquinic acids & $69.02 \pm 1.38 b$ & $89.00 \pm 1.78 \mathrm{a}$ & nd & $31.51 \pm 0.63 c$ \\
\hline 120 & Di-caffeoylquinic & $4.81 \pm 0.10 \mathrm{~b}$ & $17.66 \pm 0.35 a$ & nd & $2.79 \pm 0.06 c$ \\
\hline 121 & Dicaffeoylquinic & $4.12 \pm 0.08 c$ & $12.78 \pm 0.26 a$ & nd & $1.33 \pm 0.03 c$ \\
\hline 124 & Caffeoyl dihexoside & $13.38 \pm 0.27 a$ & $8.47 \pm 0.17 b$ & nd & $2.04 \pm 0.04 c$ \\
\hline 125 & Caffeoyl dihexoside & $3.51 \pm 0.07 \mathrm{~b}$ & $6.26 \pm 0.13 a$ & nd & $2.23 \pm 0.04 c$ \\
\hline \multirow[t]{3}{*}{126} & Caffeoyl dihexoside & nd & nd & $6.64 \pm 0.13 a$ & nd \\
\hline & SUM & $1431.68 \pm 28.63 b$ & $2044.37 \pm 40.89 a$ & $6.64 \pm 0.13 \mathrm{~d}$ & $361.16 \pm 7.22 \mathrm{c}$ \\
\hline & Anthocyanins & & & & \\
\hline 21 & Cyanidin 3,5-O-diglucoside & $19.56 \pm 0.39 a$ & nd & nd & nd \\
\hline 46 & Cyanidin 3-O-glucoside & $339.87 \pm 6.80 \mathrm{a}$ & nd & nd & nd \\
\hline 76 & Cyanidin 3-O-malonylglucoside & $154.35 \pm 3.09 a$ & nd & nd & nd \\
\hline 90 & Cyanidin 3-O-malonylglucoside & $14.40 \pm 0.29 a$ & nd & nd & nd \\
\hline \multirow[t]{3}{*}{91} & Cyanidin 3-(6-O-acetyl)glucoside & $16.56 \pm 0.33 a$ & nd & nd & nd \\
\hline & SUM & $549.57 \pm 10.99 a$ & nd & nd & nd \\
\hline & Catechins and Proanthocyanins & & & & \\
\hline 31 & $(+)$-Catechin & $46.77 \pm 0.94 d$ & $160.08 \pm 3.20 b$ & $374.41 \pm 7.49 a$ & $133.37 \pm 2.67 c$ \\
\hline 36 & B-type (epi)catechin dimmer & $111.05 \pm 2.22 \mathrm{a}$ & $33.03 \pm 0.66 b$ & nd & $28.85 \pm 0.58 c$ \\
\hline 38 & B-type (epi)catechin dimmer & nd & $19.88 \pm 0.40 \mathrm{~b}$ & $383.49 \pm 7.67 a$ & nd \\
\hline 39 & B-type (epi)catechin dimmer & $136.33 \pm 2.73 a$ & $15.04 \pm 0.30 c$ & nd & $125.77 \pm 2.52 b$ \\
\hline 40 & (-)-Epicatechin & $656.57 \pm 13.13 b$ & $138.19 \pm 2.76 \mathrm{~d}$ & $700.12 \pm 14.00 \mathrm{a}$ & $457.66 \pm 9.15 c$ \\
\hline 43 & B-type (epi)catechin trimmer & nd & nd & nd & $86.20 \pm 1.72 a$ \\
\hline 57 & B-type (epi)catechin tetramer & $120.62 \pm 2.41 c$ & $45.32 \pm 0.91 d$ & $448.56 \pm 8.97 a$ & $142.85 \pm 2.86 b$ \\
\hline 59 & B-type (epi)catechin tetramer & $57.12 \pm 1.14 \mathrm{a}$ & $22.38 \pm 0.45 b$ & $21.69 \pm 0.43 b$ & $18.43 \pm 0.37 c$ \\
\hline
\end{tabular}


Table 2. Cont.

\begin{tabular}{|c|c|c|c|c|c|}
\hline & Compounds & Flower & Leaves & Roots & Stalk \\
\hline 63 & B-type (epi)catechin dimmer & $760.26 \pm 15.21 b$ & $305.55 \pm 6.11 c$ & $796.86 \pm 15.94 a$ & $214.39 \pm 4.29 \mathrm{~d}$ \\
\hline 74 & A-type procyanidin tetramer & nd & nd & $51.53 \pm 1.03 a$ & nd \\
\hline 80 & B-type (epi)catechin tetramer & nd & nd & $105.67 \pm 2.11 \mathrm{a}$ & nd \\
\hline \multirow{2}{*}{83} & SUM & $1888.72 \pm 37.77 \mathrm{~b}$ & $739.47 \pm 14.79 \mathrm{~d}$ & $3239.19 \pm 64.78 \mathrm{a}$ & $1207.52 \pm 24.15 c$ \\
\hline & Flavonols & & & & \\
\hline 45 & Quercetin 3-O-glucoside & nd & $15.00 \pm 0.30 a$ & nd & $4.15 \pm 0.08 b$ \\
\hline 101 & Quercetin 3-O-(6"-galloylglucose) & nd & $77.72 \pm 1.55 a$ & nd & nd \\
\hline 103 & Taxifolin 7-O- $\beta$-D-glucopyranoside & nd & nd & $43.41 \pm 0.87 a$ & nd \\
\hline 105 & Quercetin-glucoside-rhamnoside-rhamnoside & $26.29 \pm 0.53 a$ & $9.93 \pm 0.20 c$ & nd & $13.33 \pm 0.27 b$ \\
\hline 107 & Quercetin rhamnosyl-rutinoside & $5.93 \pm 0.12 a$ & $3.11 \pm 0.06 b$ & nd & $2.54 \pm 0.05 b$ \\
\hline 109 & Quercetin 3-O-glucuronide & $494.97 \pm 9.90 c$ & $1645.76 \pm 32.92 a$ & $4.13 \pm 0.08 \mathrm{~d}$ & $675.15 \pm 13.50 b$ \\
\hline 112 & Quercetin 3-O-acetyl glucoside & $47.89 \pm 0.96 b$ & $54.56 \pm 1.09 a$ & nd & $26.73 \pm 0.53 c$ \\
\hline \multirow[t]{4}{*}{117} & Kaempferol 3-O-glucuronide & $137.89 \pm 2.76 b$ & $163.18 \pm 3.26 \mathrm{a}$ & nd & $65.65 \pm 1.31 c$ \\
\hline & SUM & $718.2 \pm 14.36 c$ & $1969.85 \pm 39.40 \mathrm{a}$ & $47.54 \pm 0.95 \mathrm{~d}$ & $787.86 \pm 15.76 b$ \\
\hline & Sanguisorbigenin & $262.53 \pm 5.25 b$ & $300.60 \pm 6.01 \mathrm{a}$ & nd & $253.28 \pm 5.07 \mathrm{c}$ \\
\hline & Total mg/100 g d.w. & $14444.97 \pm 288.90 \mathrm{a}$ & $9962.55 \pm 199.25 b$ & $8687.16 \pm 173.74 \mathrm{c}$ & $4606.33 \pm 92.13 c$ \\
\hline
\end{tabular}

${ }^{+}$Values are expressed as the mean $(n=3) \pm$ standard deviation and different letters (between morphological parts) within the same row indicates statistically significant differences $(p<0.05) ;{ }^{\ddagger}$ nd, not identified. 
Tannins are compounds that occur naturally in plants and also play a defensive role in them. They exhibit anti-inflammatory properties against inflammation of the mucous membranes and skin, as well as antiastringent, antioxidative, free radical-scavenging, and antiproliferative properties. In addition, they are also an important component of food because they affect its storage stability, taste, and color [30]. The highest content of these compounds was recorded in the flowers ( $9594.27 \mathrm{mg} / 100 \mathrm{~g}$ d.b.) and the lowest one in the stalks $(1996.51 \mathrm{mg} / 100 \mathrm{~g}$ d.b.). According to Karkanis et al. [3], their content in S. minor was comparable in the leaves and stalks while 4 times higher in the roots compared to the morphological parts of S. officinalis L., respectively. In turn, the major compound in all morphological parts tested was Lambertian C, with its content ranging from $62 \%$ in the roots to $17 \%$ in the stalks, and similar observations were made in S. minor [3].

Phenolic acids are another naturally occurring class of polyphenolic compounds that have a number of biological properties, including antioxidative ones, or are used in the prevention of cardiovascular diseases. They also affect the sour and bitter taste of food of plant origin, imparting them astringent flavones [31]. They dominated in the leaves of S. officinalis L. and their content amounted to $2044.37 \mathrm{mg} / 100 \mathrm{~g}$ d.b., while their poorest presence was in the roots (only $6.64 \mathrm{mg} / 100 \mathrm{~g}$ d.b.). Their content in the leaves was 5.3 times higher compared to their total content in leaves and stalks of S. minor, but similar while comparing to the stalks of S. officinalis L. and S. minor [3]. In turn, chlorogenic acid turned out to be the major compound in the flowers, neochlorogenic acid prevailed in the stalks and leaves, while ellagic acid was found in the leaves and stalks of S. minor [3].

Anthocyanins occurred only in flowers, giving them an intense red color. They belong to the group of polyphenols which show a number of health-promoting properties [9,32]. Their content was $549.57 \mathrm{mg} / 100 \mathrm{~g}$ d.b., and the dominant compounds were cyanidin 3-O-glucoside and cyanidin $3-O-$ malonylglucoside and they constituted of $62 \%$ and $28 \%$ of all anthocyanins, respectively.

Catechins and proanthocyanidins are compounds that also play an important role in the prevention of many diseases [9,32]. Their content ranged from 739.47 to $3239.19 \mathrm{mg} / 100 \mathrm{~g}$ d.b. in the leaves and roots of S. officinalis L, respectively, and was 5.6 and 20 times higher compared to the leaves and roots of Fallopia japonica, respectively [9]. The dominant compounds were: B-type (epi)catechin dimmer constituting $41 \%$ in the leaves to $18 \%$ in the stalks of all flavan-3-ols, and (-)-epicatechin constituting from $37 \%$ in the stalks to $19 \%$ in the leaves. Although in F. japonica, the major compound was procyanidin dimer B [9].

Flavonols are also a valuable class of natural secondary metabolites due to their anti-inflammatory and antioxidative properties [9]. The highest content of these compounds was noted in the leaves and reached $1969.85 \mathrm{mg} / 100 \mathrm{~g}$ d.b. It was $2.7,2.5$, and 41 times higher compared to the flowers, stalks, and roots, respectively. This difference results from the fact that these compounds are mainly located in the top layer of plants, protecting them from harmful UV radiation [32]. In turn, quercetin-O-glucuronide was the dominant compound in the flowers, leaves, and stalks, constituting $69 \%, 83 \%$, and $85 \%$ of all flavonols, respectively, whereas taxifolin $7-O-\beta$-D-glucopyranoside prevailed in the roots, constituting $91 \%$. These observations have also been confirmed by Kim et al. [1].

\subsection{Pro-Health Properties}

The average antioxidative activity determined for S. officinalis L. was $4.45 \mathrm{mmol}$ Troloxu (TE)/g dry basis (d.b.) in the ABTS test and $0.18 \mathrm{mmol} \mathrm{TE} / \mathrm{g}$ d.b. in the FRAP assay (Table 3). The highest activity was determined in the leaves and was 6.63 and $0.30 \mathrm{mmol} \mathrm{TE} / \mathrm{g}$ d.b. in the ABTS and FRAP tests, respectively. It was 1.2 and 1.6 times higher than in the stalks, 12.0 and 2.1 times higher than in the roots, and comparable to that found in the flowers for the ABTS radicals and for $\mathrm{Fe}^{3+}$ reduction to $\mathrm{Fe}^{2+}$, respectively (Table 3). Similar results of the antioxidative activity assays were obtained for the roots of S. officinalis gathered in China [5]. In turn, previous research shows that the antiradical activity of the leaves, stalks, and roots of S. officinalis L. was 6.2,1.7, and 10.6 times higher compared to the same parts of F. japonica as well as 7.9, 1.8, and 9.3 times higher compared to the same parts of $F$. sachalinensis, respectively [9]. Antiradical activity for the roots was comparable to that obtained for the medical 
plant-Ruta montana [33]. Moreover, the average reducing activity of the tested parts of S. officinalis L. was comparable to the antioxidant potential determined for Melissae folium and about 6 times higher than for Spiraea herba, Uvae ursi folium, Rubi fructose folium, or Fragariae herba folium [34]. Thus, the results obtained indicate that the roots, flowers, and leaves of $S$. officinalis L. have a high ability to scavenge free radicals, which may be due to the high content of bioactive compounds determined for these morphological parts of the plant. What's more, the results presented a strong Pearson's correlation with the sum content of phenolic acids and anthocyanins and with the antioxidative activity as $r^{2}=0.734$ and 0.539 for ABTS assay and $r^{2}=0.746$ and 0.869 for FRAP, whereas the correlation between the reducing activity and sum of hydrolysable tannins and polyphenols was also strong $r^{2}=0.769$ and 0.823 .

Table 3. The antioxidant activity and the biological activity in vitro.

\begin{tabular}{|c|c|c|c|c|c|}
\hline Components & $\begin{array}{c}\alpha \text {-Amylase } \\
{\left[\mathrm{EC}_{50} \mathrm{MG} / \mathrm{ML}\right]}\end{array}$ & $\begin{array}{l}\alpha \text {-Glucosidase } \\
{\left[\mathrm{EC}_{50} \mathrm{MG} / \mathrm{ML}\right]}\end{array}$ & $\begin{array}{l}\text { Pancreatic Lipase } \\
{\left[\mathrm{EC}_{50} \mathrm{MG} / \mathrm{ML}\right]}\end{array}$ & ABTS [mmol/g d.b.] & FRAP [mmol/g d.b.] \\
\hline Leaves & $9.48 \pm 0.24 b \neq$ & $11.86 \pm 0.24 b$ & $18.75 \pm 0.38 a$ & $6.63 \pm 0.1 \mathrm{a} 3$ & $0.30 \pm 0.01 \mathrm{a}$ \\
\hline Flowers & $6.03 \pm 0.19 a$ & $9.60 \pm 0.19 a$ & $21.40 \pm 0.43 b$ & $5.56 \pm 0.11 b$ & $0.20 \pm 0.01 b$ \\
\hline Stalks & $23.91 \pm 0.63 c$ & $31.74 \pm 0.63 \mathrm{~d}$ & $56.47 \pm 1.13 c$ & $0.52 \pm 0.01 d$ & $0.09 \pm 0.01 \mathrm{~d}$ \\
\hline Roots & $10.44 \pm 0.39 b$ & $19.54 \pm 0.39 c$ & $72.68 \pm 1.45 \mathrm{~d}$ & $5.08 \pm 0.10 c$ & $0.13 \pm 0.01 c$ \\
\hline
\end{tabular}

$\ddagger$ Values are expressed as the mean $(n=3) \pm$ standard deviation and different letters (between morphological parts) within the same row indicates statistically significant differences $(p<0.05)$.

The leaves, flowers, stalks, and roots of $S$. officinalis L. were also tested for their ability of inhibition of $\alpha$-amylase ( $\alpha \mathrm{A})$ and $\alpha$-glucosidase $(\alpha \mathrm{G})$ activity, and their ability of inhibition of pancreatic lipase (LP) activity (Table 3). $\alpha \mathrm{A}$ and $\alpha \mathrm{G}$ are carbohydrate-degrading enzymes, but the mechanisms of their action differ; $\alpha \mathrm{A}$ accelerates the hydrolysis of bonds inside a compound, whereas $\alpha \mathrm{G}$ hydrolyzes $\alpha-1,4$-glucosidic bonds, leading to the release of glucose absorbed by the body [35]. In turn, LP is an enzyme responsible for the degradation of triglycerides to simple lipids and fatty acids absorbable by the human body. However, it has been proved that excess fatty acids can lead to the formation of free radicals and insulin resistance [36]. Therefore, the inhibition of the above enzymes may be used in the treatment of diabetes type II or obesity [35]. The obtained results show that the highest ability to inhibit $\alpha \mathrm{A}$ and $\alpha \mathrm{G}$ activity was recorded for flowers of $S$. officinalis $\mathrm{L}$. and reached $\mathrm{EC}_{50} 6.03$ and $9.60 \mathrm{mg} / \mathrm{mL}$, respectively. Therefore, the flowers were 1.6 and 1.3 times more active than the leaves, 4.0 and 3.3 times more active than the stalks, and 1.7 and 2.0 times more active than the roots, respectively. In turn, the highest ability to inhibit pancreatic lipase was found for the leaves of S. officinalis L. $\left(\mathrm{EC}_{50}=18.75 \mathrm{mg} / \mathrm{mL}\right)$ which were 1.2, 3.0, and 3.9 times more active compared to the flowers, stalks, and roots of the tested plant, respectively. As far as the results showed that the ability to inhibit $\alpha \mathrm{A}$, $\alpha \mathrm{G}$, and LP strongly depended on the sum of flavan-3-ols and the correlations were $r^{2}=0.944,0.836$, and 0.593 , respectively. However, in the case of phenolic acids and flavonols, the correlations were strongly negative: $r^{2}=0.813,0.921$, and 0.872 and $r^{2}=0.842,0.825$, and 0.857 , respectively.

The antiproliferative potency of the flowers, leaves, roots, and stems of S. officinalis L. were tested against four different cancer cell lines as BxPC3 (pancreatic ductal adenocarcinoma), DLD-1 (colorectal adenocarcinoma), HCV29T (bladder cancer), and Jurkat (T-cell leukemia). This is the first report on these cancer cell lines. The effect against the used cell lines was clearly noted (Figure 1). The extract from S. officinalis L. leaves significantly reduces the viability of all tested cell lines, especially DLD-1 colon cancer cells (to 19\%) and Jurkat leukemia cells (to $22 \%$ ). The flower extract reduced the viability of Jurkat cells to $32 \%$ and the remaining cells by $39-50 \%$. Extract from the root showed similar results. In contrast, the extract from the stem acted the weakest on all cell lines, reducing cell viability to $85-97 \%$. What's more, the results presented a strong Pearson's correlation between the sum of flavan-3-ols and with the viability of Jurkat leukemia cells and DLD-1 colon cancer cells $-r^{2}=0.731$ and 0.545 , while lower the viability of HCV29T cells strongly depended on anthocyanins and the correlation was $r^{2}=0.705$. Liu et al. [37] noted that aqueous root extracts of S. officinalis L. showed synergic effect on inhibition of activity against HCT-116 and CPR cell lines 
(colon cancer) with 5-fluorouracil. Shin et al. [38] observed that the extract of S. officinalis L. inhibited cell growth against HSC4 and HN22 cell line (oral cancer) and induced death. According to Liu et al. [39], aqueous plant extracts of $S$. officinalis L. decreased the target Wnt and $\beta$-catenin genes by inhibiting the signal pathway of Wnt/ $\beta$-catenin in cells of colorectal cancer. Moreover, Karkanis et al. [3] noted that the highest ability to inhibit of cervical carcinoma (HeLa), breast adenocarcinoma (MCF-7), and nonsmall cell lung cancer (NCl-H460) cell line was recorded for extract of roots of S. minor, whereas the extract of leaves + stalks of $S$. minor showed high ability to inhibit of hepatocellular carcinoma (HepG2) cell line. Thus, our own results and other authors presented that the highest cytotoxicity for the examined tumor cell lines covered depends on the analyzed morphological parts of S. officinalis L. and their bioactive substances. Moreover, the leaves, flowers, and roots showed high and differed antiproliferative potency to inhibit activity of various tumor cell lines.
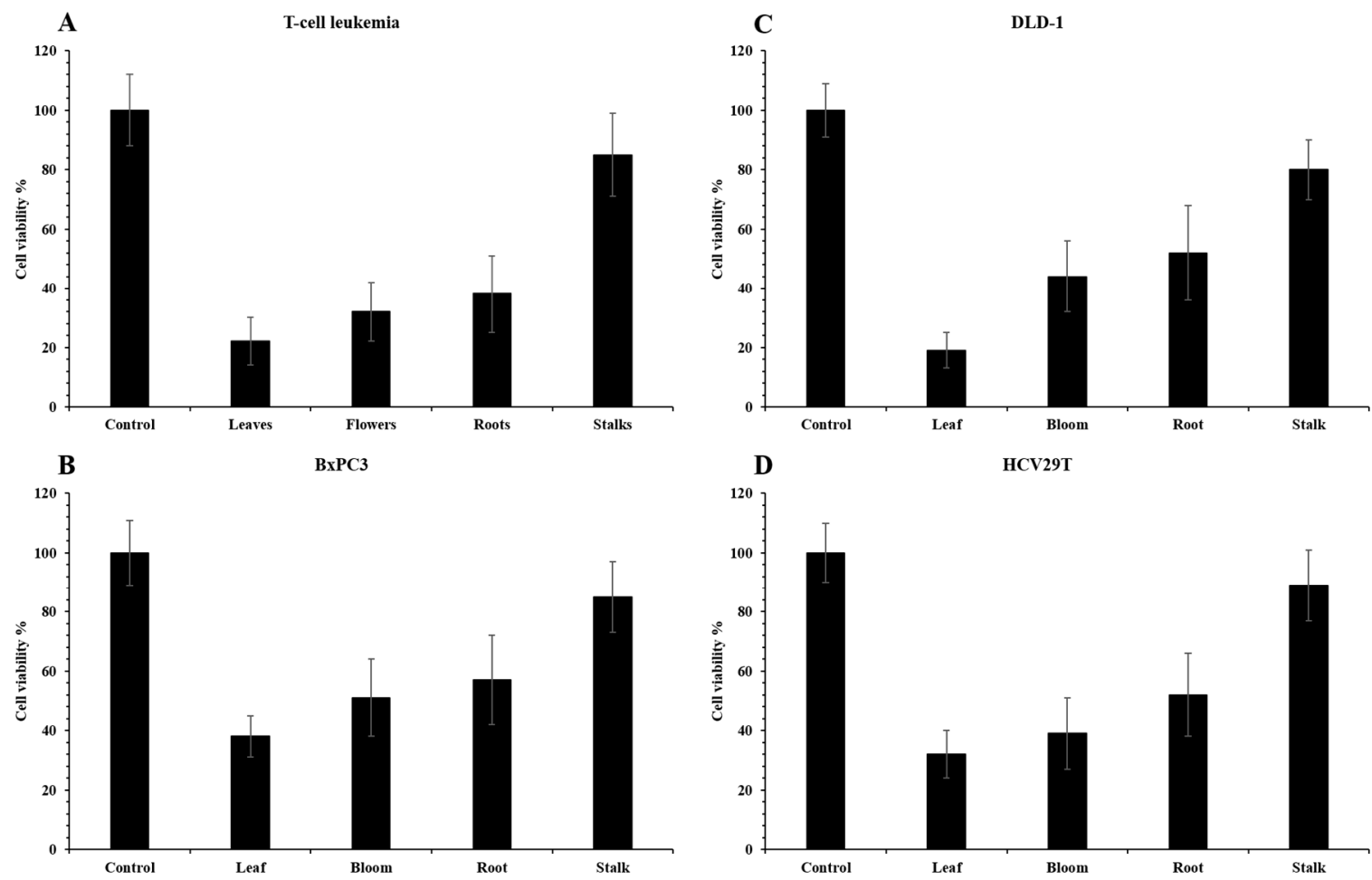

Figure 1. Cell viability of Jurkat (A), BxPC3 (B), DLD-1 (C), and HCV29T (D) cell lines after treatment with plant extracts for $48 \mathrm{~h}$. Data are presented as means SD normalized to untreated control ( $1 \%$ ethanol).

\section{Materials and Methods}

\subsection{Material, Reagents, and Instruments}

Materials: Sanguisorba officinalis L. flowers, stalks, roots, and leaves $(\sim 5 \mathrm{~kg})$ were obtained from

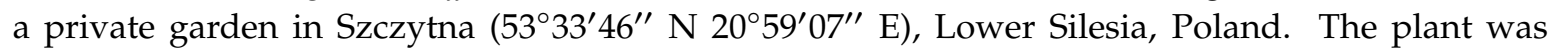
collected randomly in August 2019 from different parts of field (total area of cultivation is 1 ha). Then, material was washed and dried in a freeze dryer Alpha 1-4 LSC (Christ, Osterode, Germany).

Reagents: acetonitrile, formic acid, methanol, ABTS (2,2' -azinobis(3-ethylbenzothiazoline-6-sulfonic acid), 6-hydroxy-2,5,7,8-tetramethylchroman-2-carboxylic acid (Trolox), 2,4,6-tri(2-pyridyl)-s-triazine (TPTZ), methanol, acetic acid, $\alpha$-amylase from porcine pancreas, $\alpha$-glucoamylase from Rhizopus sp., lipase from porcine pancreas, Antibiotic-Antimycotic Solution, and RPMI 1640 culture medium were purchased from Sigma-Aldrich (Steinheim, Germany). (-)-Epicatechin, (+)-catechin, procyanidin B2, p-coumaric acid, ferulic acid, 5-caffeoylquinic acid, procyanidin A2, caffeic acid, quercetin 3-O-rutinoside, quercetin-3-O-galactoside, quercetin-3-O-glucoside, 
kaempferol 3-O-galactoside, ellagic acid, and cyanidin-3-O-glucoside were purchased from Extrasynthese (Lyon, France). DMEM culture medium with 10\% FBS were purchased from Gibco (Thermo Fisher Scientific, Waltham, MA, USA), and MTS solution was purchased from Promega (Madison, WI, USA).

Instruments: UV-2401 PC spectrophotometer (Shimadzu, Kyoto, Japan) for antioxidant activity; Sonic 6D, Polsonic, Warsaw, Poland, for extraction; LC-DAD-ESI-QTOF-MS/MS (ultraperformance liquid chromatography equipped with a binary solvent manager and a Q-Tof Micro Mass Spectrometer (Waters, Manchester, UK) with an ESI source operating in negative and positive modes (Waters Corporation, Milford, MA, USA) for polyphenolic compounds; and Wallac 1420 VICTOR2 Plate Reader (PerkinElmer, Waltham, MA, USA) for antiproliferative activity.

\subsection{Determination of Polyphenols}

For the extraction and determination of phenolic compounds, a protocol described before by Lachowicz et al. [9] was followed. Briefly, samples $(0.1 \mathrm{~g})$ were mixed with $5 \mathrm{~mL}$ of $30 \%$ of UPLC-grade methanol. The extracts were sonicated for $20 \mathrm{~min}$ and centrifuged (at $19,000 \times \mathrm{g} / 10 \mathrm{~min}$ ). Finally, the extracts were filtered by hydrophilic PTFE $0.20 \mu \mathrm{m}$ membrane (Millex Samplicity Filter, Darmstadt, Germany) and used for testing.

The runs were monitored at the following wavelengths: phenolic acids at $320 \mathrm{~nm}$, flavonols at $360 \mathrm{~nm}$, anthocyanins at $520 \mathrm{~nm}$, flavan-3-ols at $280 \mathrm{~nm}$, and hydrolysable tannins at $240 \mathrm{~nm}$. Separations of individual polyphenols were carried out using a UPLC BEH C18 column $(1.7 \mu \mathrm{m}$, $2.1 \mathrm{~mm} \times 100 \mathrm{~mm})$ at $30{ }^{\circ} \mathrm{C}$. The samples $(10 \mu \mathrm{L})$ were injected, and the elution was completed in $15 \mathrm{~min}$ with a sequence of linear gradients and isocratic flow rates of $0.45 \mathrm{~mL} / \mathrm{min}$. The mobile phase consisted of solvent A ( $0.1 \%$ formic acid, $\mathrm{v} / \mathrm{v})$ and solvent B ( $100 \%$ acetonitrile). The program began with isocratic elution with $99 \%$ solvent $A(0-1 \mathrm{~min})$, and then, a linear gradient was used until $12 \mathrm{~min}$, lowering solvent A to $0 \%$; from 12.5 to $13.5 \mathrm{~min}$, the gradient returned to the initial composition $(99 \% \mathrm{~A})$, and then, it was held constant to re-equilibrate the column. The analysis was carried out using full-scan, data-dependent MS scanning from $\mathrm{m} / \mathrm{z} 100$ to 1500 . Leucine enkephalin was used as the reference compound at a concentration of $500 \mathrm{pg} / \mu \mathrm{L}$, at a flow rate of $2 \mu \mathrm{L} / \mathrm{min}$, and the $[\mathrm{M}-\mathrm{H}]^{-}$ion at $554.2615 \mathrm{Da}$ was detected. The $[\mathrm{M}-\mathrm{H}]^{-}$ion was detected during $15 \mathrm{~min}$ analysis performed within ESI-MS accurate mass experiments, which were permanently introduced via the LockSpray channel using a Hamilton pump. The lock mass correction was \pm 1.000 for the mass window. The mass spectrometer was operated in negative- and positive-ion mode, set to the base peak intensity (BPI) chromatograms, and scaled to 12,400 counts per second (cps) (100\%). The optimized MS conditions were as follows: capillary voltage of $2500 \mathrm{~V}$, cone voltage of $30 \mathrm{~V}$, source temperature of $100^{\circ} \mathrm{C}$, desolvation temperature of $300{ }^{\circ} \mathrm{C}$, and desolvation gas (nitrogen) flow rate of $300 \mathrm{~L} / \mathrm{h}$. Collision-induced fragmentation experiments were performed using argon as the collision gas, with voltage ramping cycles from 0.3 to $2 \mathrm{~V}$. Characterization of the single components was carried out via the retention time and the accurate molecular masses. Each compound was optimized to its estimated molecular mass [M $\mathrm{H}]^{-} /[\mathrm{M}+\mathrm{H}]^{+}$in the negative and positive mode before and after fragmentation. The data obtained from UPLC-MS were subsequently entered into the MassLynx 4.0ChromaLynx Application Manager software. On the basis of these data, the software is able to scan different samples for the characterized substances. The PDA spectra were measured over the wavelength range of $200-800 \mathrm{~nm}$ in steps of $2 \mathrm{~nm}$. The calibration curves were prepared for the standard: gallic acid ( $\mathrm{y}=1222.5 \mathrm{x}-1972.7$; $\left.r^{2}=0.9999\right)$, procyanidin B2 $\left(\mathrm{y}=6566.2 \mathrm{x}-15,957 ; r^{2}=0.9999\right),(+)$-catechin $(\mathrm{y}=1565.9 \mathrm{x}+2243$; $\left.r^{2}=0.9999\right), p$-coumaric acid $\left(\mathrm{y}=68.109 \mathrm{x}+49.224 ; r^{2}=0.9996\right)$, ferulic acid $\left(\mathrm{y}=50,215 \mathrm{x}+36,206 ; r^{2}=\right.$ 0.9997), 5-caffeoylquinic acid $\left(\mathrm{y}=14,332 \mathrm{x}+1315.1 ; r^{2}=0.9999\right)$, procyanidin $\mathrm{A} 2(\mathrm{y}=9484.1 \mathrm{x}-6770.5$; $\left.r^{2}=0.9997\right)$, caffeic acid $\left(\mathrm{y}=17,431 \mathrm{x}+40,114 ; r^{2}=0.9999\right)$, quercetin 3-O-rutinoside $(\mathrm{y}=13,362 \mathrm{x}-$ $\left.1795 ; r^{2}=0.9997\right)$, qercetin-3-O-galactoside $\left(\mathrm{y}=20,926 \mathrm{x}-18,309 ; r^{2}=0.9991\right)$, qercetin-3-O-glucoside $\left(\mathrm{y}=11,923 \mathrm{x}+8188 ; r^{2}=0.9999\right)$, kaempferol 3-O-galactoside $\left(\mathrm{y}=12,057 \mathrm{x}-1922.4 ; r^{2}=0.9997\right)$, ellagic acid ( $\left.\mathrm{y}=26754 \mathrm{x}+172359 ; r^{2}=0.9995\right)$, cyanidin-3-O-glucoside $\left(\mathrm{y}=30,726 \mathrm{x}+190,297 ; r^{2}=\right.$ 
0.9976), and (-)-epicatechin $\left(y=39,233 x-360,853 ; r^{2}=0.9994\right)$ at concentrations ranging between 0.05 and $0.5 \mathrm{mg} / \mathrm{mL}$. All data were obtained in triplicate. The results were expressed as $\mathrm{mg} / 100 \mathrm{~g}$ of dry basis (d.b.).

\subsection{Pro-Health Properties}

\subsubsection{Antiradical Capacity}

Samples $(1 \mathrm{~g})$ were mixed with methanol $(80 \% ; 10 \mathrm{~mL})$ and then with hydrochloric acid $(1 \%)$. This process was performed twice by incubating the above slurry for $20 \mathrm{~min}$ under sonication. Next, the slurry was centrifuged at $19,000 \times g$ for $10 \mathrm{~min}$, and the supernatant was filtered through a hydrophilic PTFE $0.20 \mu \mathrm{m}$ membrane (Merck, Darmstadt, Germany) and used for analysis.

The ABTS method was carried out with the method described by Re et al. [40]. For this, $0.03 \mathrm{~mL}$ of sample was mixed with $3 \mathrm{~mL}$ of ABTS + solution, and after 6 min of reaction, the absorbance was measured at $734 \mathrm{~nm}$ using the spectrophotometer. All data were obtained in triplicate. The activity was expressed in mmol Trolox/g d.b.

\subsubsection{Reducing Potential}

The FRAP method was carried out with the method described by Benzie et al. [41]. The reagent was prepared by mixing $10 \mathrm{mmol}$ 2,4,6-Tris(2-pyridyl)-s-triazine (TPTZ)/L reagent with $20 \mathrm{mmol} / \mathrm{L}$ ferric chloride in acetate buffer (pH 3.6). Precisely, $0.1 \mathrm{~mL}$ of sample was mixed with $0.9 \mathrm{~mL}$ of distilled water and $3 \mathrm{~mL}$ of ferric complex. After $10 \mathrm{~min}$ of reaction, the absorbance was measured at $593 \mathrm{~nm}$ using the spectrophotometer. All data were obtained in triplicate. The activity was expressed in mmol Trolox/g d.b.

\subsubsection{Determination of Enzyme Inhibition Potency}

Anti-diabetic activity, $\alpha$-amylase, $\alpha$-glucosidase inhibitory, and lipase activity effect of the materials were described previously by Nakai et al. [42], Podsędek et al. [43], and Nickavar et al. [44]. The extraction of mixed material was done with $70 \%$ acetone (or water) at room temperature for $60 \mathrm{~min}$ with constant stirring. After centrifuging at $4000 \mathrm{rpm}$ for $10 \mathrm{~min}$, and filtration, the supernatants were concentrated at $40^{\circ} \mathrm{C}$ (vacuum evaporator) to remove the acetone and the aqueous phase was diluted with water. For further analytical and biological activity assays, a gradient of concentrations was prepared via serial dilution of the fruit extracts in pure water. The amount of the inhibitor (expressed as $\mathrm{mg}$ of fruit per $1 \mathrm{~mL}$ of reaction mixture under assay conditions) required to inhibit $50 \%$ of the enzyme activity was defined as the $\mathrm{IC}_{50}$ value. The $\mathrm{IC}_{50}$ of the fruits tested was obtained from the line of the plot of the fruit concentration in $1 \mathrm{~mL}$ of reaction mixture versus the \% inhibition. All samples were assayed in triplicate.

\subsubsection{Antiproliferative Potency}

\section{Cell Lines and Cell Culture}

The human cancer cell lines BxPC3 (pancreatic ductal adenocarcinoma), DLD-1 (colorectal adenocarcinoma), and HCV29T (bladder cancer) were cultured in DMEM culture medium with $10 \%$ FBS and Antibiotic-Antimycotic Solution. Jurkat cell line (T-cell leukemia) was maintained in RPMI 1640 culture medium supplemented with $2 \mathrm{mM}$ L-glutamine, $100 \mathrm{U} / \mathrm{mL}$ penicillin, $100 \mu \mathrm{g} / \mathrm{mL}$ streptomycin, and $10 \%$ fetal bovine serum (FBS). All cell lines were cultured at $37^{\circ} \mathrm{C}$ in a humidified atmosphere of $5 \% \mathrm{CO}_{2}$. The cells were seeded at densities of $5 \times 10^{3}$ cells $/ 0.1 \mathrm{~mL}\left(0.32 \mathrm{~cm}^{2}\right)$ for cell viability assay. All cell lines were obtained from the collection of the Institute of Immunology and Experimental Therapy, Polish Academy of Sciences, Wroclaw, Poland. 


\section{Determination of Cell Viability}

For determination of cell viability, cells were seeded in 96-well-plate (NUNC, Roskilde, Denmark). The plant extract was prepared by suspending $100 \mathrm{mg}$ of dry plant material in $1 \mathrm{~mL}$ of $30 \%$ ethanol. The suspension was heated at $50{ }^{\circ} \mathrm{C}$ for $30 \mathrm{~min}$ and then centrifuged at $10,000 \times g$ for $15 \mathrm{~min}$. The clear supernatant was diluted 30 -fold in cell culture medium. As a control, $1 \%$ ethanol in the cell medium was used. The cells were incubated in $200 \mu \mathrm{L}$ of the above culture medium for $48 \mathrm{~h}$. Following the incubation, $20 \mu \mathrm{L}$ of MTS solution was added to each well for $4 \mathrm{~h}$; next, absorbance at $490 \mathrm{~nm}$ was recorded by a plate reader. Each treatment within a single experiment was performed in triplicate. Data were normalized to control medium containing $1 \%$ ethanol.

\subsection{Statistical Analysis}

Statistical analysis such as one-way ANOVA $(p<0.05)$ was analyzed using Statistica 12.5 (StatSoft, Kraków, Poland).

\section{Conclusions}

It needs to be noted that the flowers and leaves of $S$. officinalis L. are a good source of polyphenols, including hydrolyzable tannins, phenolic acids, flavonols, and anthocyanins, and exhibit a significant antiradical and reducing potential. In turn, the roots and stalks are a valuable source of flavan-3-ols. The most effective the inhibition of $\alpha$-amylase, $\alpha$-glucosidase, and pancreatic lipase and antiproliferative activities, reflected in the inhibition of viability of pancreatic ductal adenocarcinoma, colorectal adenocarcinoma, and bladder cancer as well as T-cell leukemia cell, were shown by the flowers and leaves of S. officinalis L. Thus, the data provided in this work indicate the possibility of using its individual morphological parts in the prevention of selected disease entities. In addition, this plant material can be used not only in the food industry as a functional additive to food, increasing its health value, but also in the cosmetic and pharmaceutical industries as a nutraceutical. The data obtained justify the need for further research on the morphological parts of $S$. officinalis L. with special emphasis put on leaves and flowers, to identify mechanisms potentially responsible for the antiproliferative activity.

Supplementary Materials: The following are available online at http://www.mdpi.com/1424-8247/13/8/191/s1. Figure S1: LC-DAD-ESI-QTOF-MS/MS chromatogram fragile of the Sanguisorba officinalis L. flowers extract at 320 and $360 \mathrm{~nm}$; Figure S2: LC-DAD-ESI-QTOF-MS/MS chromatogram fragile of the Sanguisorba officinalis L. leaves extract at 320 and $360 \mathrm{~nm}$; Figure S3: LC-DAD-ESI-QTOF-MS/MS chromatogram fragile of the Sanguisorba officinalis L. roots extract at 320 and $360 \mathrm{~nm}$; Figure S4: LC-DAD-ESI-QTOF-MS/MS chromatogram fragile of the Sanguisorba officinalis L. stalks extract at 320 and $360 \mathrm{~nm}$.

Author Contributions: Conceptualization, S.L. and J.O.; methodology, S.L., J.O., A.R. and I.O.; validation, S.L. and J.O.; formal analysis, S.L. and J.O.; investigation, S.L. and J.O.; resources, S.L. and J.O.; data curation, S.L. and J.O.; writing — original draft preparation, S.L. and J.O.; writing-review and editing, S.L. and J.O.; visualization, S.L. and J.O.; project administration, S.L. and J.O.; and funding acquisition, S.L. and J.O. All authors have read and agreed to the published version of the manuscript.

Funding: This research received no external funding.

Acknowledgments: The work was created in a leading research team "Food\&Health".

Conflicts of Interest: The authors declare no conflicts of interest.

\section{References}

1. Kim, S.; Oh, S.; Noh, H.B.; Ji, S.; Lee, S.H.; Koo, J.M.; Choi, C.W.; Jhun, H.P. In vitro antioxidant and anti-propionibacterium acnes activities of cold water, hot water, and methanol extracts, and their respective ethyl acetate fractions, from Sanguisorba officinalis L. Roots. Molecules 2018, 23, 3001. [CrossRef]

2. Zhu, H.-L.; Chen, G.; Chen, S.-N.; Wang, Q.-R.; Wan, L.; Jian, S.-P. Characterization of polyphenolic constituents from Sanguisorba officinalis L. and its antibacterial activity. Eur. Food Res. Technol. 2019, 245, 1487-1498. [CrossRef] 
3. Karkanis, A.C.; Fernandes, A.; Vaz, J.; Petropoulos, S.A.; Georgiou, E.; Ćirić, A.; Sokovic, M.D.; Oludemi, T.; Barros, L.; Ferreira, I.C. Chemical composition and bioactive properties of Sanguisorba minor Scop. under Mediterranean growing conditions. Food Funct. 2019, 10, 1340-1351. [CrossRef]

4. Nguyen, T.T.H.; Cho, S.O.; Ban, J.Y.; Kim, J.Y.; Ju, H.S.; Koh, S.B.; Song, K.-S.; Seong, Y.H. Neuroprotective effect of Sanguisorbae radix against oxidative stress-induced brain damage: In vitro and in vivo. Boil. Pharm. Bull. 2008, 31, 2028-2035. [CrossRef]

5. Zhang, L.; Koyyalamudi, S.R.; Jeong, S.C.; Reddy, N.; Smith, P.T.; Rajendran, A.; Longvah, T. Antioxidant and immunomodulatory activities of polysaccharides from the roots of Sanguisorba officinalis. Int. J. Boil. Macromol. 2012, 51, 1057-1062. [CrossRef]

6. Wang, Z.; Loo, W.T.; Wang, N.; Chow, L.W.; Wang, N.; Han, F.; Zheng, X.; Chen, J.-P. Effect of Sanguisorba officinalis L on breast cancer growth and angiogenesis. Expert Opin. Ther. Targets 2012, 16, S79-S89. [CrossRef] [PubMed]

7. Liang, J.; Chen, J.; Tan, Z.; Peng, J.; Zheng, X.; Nishiura, K.; Ng, J.; Wang, Z.; Wang, D.; Chen, Z.; et al. Extracts of the medicinal herb Sanguisorba officinalis inhibit the entry of human immunodeficiency virus-1. J. Food Drug Anal. 2013, 21, S52-S58. [CrossRef] [PubMed]

8. Kim, Y.H.; Chung, C.B.; Kim, J.G.; Ko, K.I.; Park, S.H.; Kim, J.-H.; Eom, S.-Y.; Kim, Y.S.; Hwang, Y.-I.; Kim, K.-H. Anti-Wrinkle Activity of Ziyuglycoside I Isolated from a Sanguisorba officinalis Root Extract and Its Application as a Cosmeceutical Ingredient. Biosci. Biotechnol. Biochem. 2008, 72, 303-311. [CrossRef]

9. Lachowicz, S.; Oszmiański, J.; Wojdyło, A.; Cebulak, T.; Hirnle, L.; Siewiński, M. UPLC-PDA-Q/TOF-MS identification of bioactive compounds and on-line UPLC-ABTS assay in Fallopia japonica Houtt and Fallopia sachalinensis (F.Schmidt) leaves and rhizomes grown in Poland. Eur. Food Res. Technol. 2018, 245, 691-706. [CrossRef]

10. Yisimayili, Z.; Abdulla, R.; Tian, Q.; Wang, Y.; Chen, M.; Sun, Z.; Li, Z.; Liu, F.; Aisa, H.A.; Huang, C. A comprehensive study of pomegranate flowers polyphenols and metabolites in rat biological samples by high-performance liquid chromatography quadrupole time-of-flight mass spectrometry. J. Chromatogr. A 2019, 1604, 460472. [CrossRef] [PubMed]

11. Nawrot-Hadzik, I.; Ślusarczyk, S.; Granica, S.; Hadzik, J.; Matkowski, A. Phytochemical Diversity in Rhizomes of Three Reynoutria Species and their Antioxidant Activity Correlations Elucidated by LC-ESI-MS/MS Analysis. Molecules 2019, 24, 1136. [CrossRef] [PubMed]

12. Bunse, M.; Lorenz, P.; Stintzing, F.C.; Kammerer, D.R. Characterization of Secondary Metabolites in Flowers of Sanguisorba officinalis L. by HPLC-DAD-MS n and GC/MS. Chem. Biodivers. 2020, 17, 1900724. [CrossRef] [PubMed]

13. Sentandreu, E.; Cerdán-Calero, M.; Sendra, J.M. Phenolic profile characterization of pomegranate (Punica granatum) juice by high-performance liquid chromatography with diode array detection coupled to an electrospray ion trap mass analyzer. J. Food Compos. Anal. 2013, 30, 32-40. [CrossRef]

14. Zhu, M.-Z.; Dong, X.; Guo, M. Phenolic Profiling of Duchesnea indica Combining Macroporous Resin Chromatography (MRC) with HPLC-ESI-MS/MS and ESI-IT-MS. Molecules 2015, 20, 22463-22475. [CrossRef] [PubMed]

15. Esposito, T.; Celano, R.; Pane, C.; Piccinelli, A.L.; Sansone, F.; Picerno, P.; Zaccardelli, M.; Aquino, R.P.; Mencherini, T. Chestnut (Castanea sativa Miller.) burs extracts and functional compounds: UHPLC-UV-HRMS profiling, antioxidant activity, and inhibitory effects on Phytopathogenic Fungi. Molecules 2019, 24, 302. [CrossRef] [PubMed]

16. Fernandes, A.; Sousa, A.; Mateus, N.; Cabral, M.; De Freitas, V. Analysis of phenolic compounds in cork from Quercus suber L. by HPLC-DAD/ESI-MS. Food Chem. 2011, 125, 1398-1405. [CrossRef]

17. Mämmelä, P.; Savolainen, H.; Lindroos, L.; Kangas, J.; Vartiainen, T. Analysis of oak tannins by liquid chromatography-electrospray ionisation mass spectrometry. J. Chromatogr. A 2000, 891, 75-83. [CrossRef]

18. Mullen, W.; Yokota, T.; Lean, M.E.; Crozier, A. Analysis of ellagitannins and conjugates of ellagic acid and quercetin in raspberry fruits by LC-MSn. Phytochemistry 2003, 64, 617-624. [CrossRef]

19. Clifford, M.N.; Johnston, K.L.; Knight, S.; Kuhnert, N. Hierarchical Scheme for LC-MSnIdentification of Chlorogenic Acids. J. Agric. Food Chem. 2003, 51, 2900-2911. [CrossRef]

20. Sun, J.; Lin, L.-Z.; Chen, P. Study of the mass spectrometric behaviors of anthocyanins in negative ionization mode and its applications for characterization of anthocyanins and non-anthocyanin polyphenols. Rapid Commun. Mass Spectrom. 2012, 26, 1123-1133. [CrossRef] 
21. Brar, H.S.; Singh, Z.; Swinny, E. Dynamics of anthocyanin and flavonol profiles in the 'Crimson Seedless' grape berry skin during development and ripening. Sci. Hortic. 2008, 117, 349-356. [CrossRef]

22. Rockenbach, I.I.; Jungfer, E.; Ritter, C.; Santiago-Schübel, B.; Thiele, B.; Fett, R.; Galensa, R. Characterization of flavan-3-ols in seeds of grape pomace by CE, HPLC-DAD-MSn and LC-ESI-FTICR-MS. Food Res. Int. 2012, 48, 848-855. [CrossRef]

23. Ito, C.; Oki, T.; Yoshida, T.; Nanba, F.; Yamada, K.; Toda, T. Characterisation of proanthocyanidins from black soybeans: Isolation and characterisation of proanthocyanidin oligomers from black soybean seed coats. Food Chem. 2013, 141, 2507-2512. [CrossRef] [PubMed]

24. Abad-García, B.; Garmón-Lobato, S.; Berrueta, L.; Gallo, B.; Vicente, F. Practical guidelines for characterization ofO-diglycosyl flavonoid isomers by triple quadrupole MS and their applications for identification of some fruit juices flavonoids. J. Mass Spectrom. 2009, 44, 1017-1025. [CrossRef] [PubMed]

25. Lin, Y.-S.; Tsai, Y.-J.; Tsay, J.-S.; Lin, J.-K. Factors Affecting the Levels of Tea Polyphenols and Caffeine in Tea Leaves. J. Agric. Food Chem. 2003, 51, 1864-1873. [CrossRef]

26. López-García, J.; Kucekova, Z.; Humpolíček, P.; Mlček, J.; Saha, P. Polyphenolic Extracts of Edible Flowers Incorporated onto Atelocollagen Matrices and Their Effect on Cell Viability. Molecules 2013, 18, 13435-13445. [CrossRef]

27. Zeng, Y.; Deng, M.; Lv, Z.; Peng, Y. Evaluation of antioxidant activities of extracts from 19 Chinese edible flowers. SpringerPlus 2014, 3, 315. [CrossRef]

28. Elfalleh, W. Total phenolic contents and antioxidant activities of pomegranate peel, seed, leaf and flower. J. Med. Plants Res. 2012, 6, 4724-4730. [CrossRef]

29. Loza-Mejía, M.A.; Salazar, J.R. Sterols and triterpenoids as potential anti-inflammatories: Molecular docking studies for binding to some enzymes involved in inflammatory pathways. J. Mol. Graph. Model. 2015, 62, 18-25. [CrossRef]

30. Arapitsas, P. Hydrolyzable tannin analysis in food. Food Chem. 2012, 135, 1708-1717. [CrossRef]

31. Parus, A. Antioxidant and pharmacological properties of phenolic acids. Postepy Fitoter. 2012, 1, 48-53.

32. Lachowicz, S.; Oszmiański, J. Profile of Bioactive Compounds in the Morphological Parts of Wild Fallopia japonica (Houtt) and Fallopia sachalinensis (F. Schmidt) and Their Antioxidative Activity. Molecules 2019, 24, 1436. [CrossRef] [PubMed]

33. Djeridane, A.; Yousfi, M.; Nadjemi, B.; Boutassouna, D.; Stocker, P.; Vidal, N. Antioxidant activity of some algerian medicinal plants extracts containing phenolic compounds. Food Chem. 2006, 97, 654-660. [CrossRef]

34. Katalinic, V.; Milos, M.; Kulisic, T.; Jukić, M. Screening of 70 medicinal plant extracts for antioxidant capacity and total phenols. Food Chem. 2006, 94, 550-557. [CrossRef]

35. Kunyanga, C.N.; Imungi, J.K.; Okoth, M.W.; Biesalski, H.K.; Vadivel, V. Total phenolic content, antioxidant and antidiabetic properties of methanolic extract of raw and traditionally processed Kenyan indigenous food ingredients. LWT 2012, 45, 269-276. [CrossRef]

36. Koska, J.; Yassine, H.; Trenchevska, O.; Sinari, S.; Schwenke, D.C.; Yen, F.T.; Billheimer, D.; Nelson, R.W.; Nedelkov, B.; Reaven, P.D. Disialylated apolipoprotein C-III proteoform is associated with improved lipids in prediabetes and type 2 diabetes1[S]. J. Lipid Res. 2016, 57, 894-905. [CrossRef]

37. Liu, M.-P.; Liao, M.; Dai, C.; Chen, J.-F.; Yang, C.-J.; Liu, M.; Chen, Z.-G.; Yao, M.-C. Sanguisorba officinalis L synergistically enhanced 5-fluorouracil cytotoxicity in colorectal cancer cells by promoting a reactive oxygen species-mediated, mitochondria-caspase-dependent apoptotic pathway. Sci. Rep. 2016, 6, 34245. [CrossRef]

38. Shin, J.-A.; Kim, J.-S.; Kwon, K.-H.; Nam, J.-S.; Jung, J.-Y.; Cho, N.-P.; Cho, S.-D. Apoptotic effect of hot water extract of Sanguisorba officinalis L. in human oral cancer cells. Oncol. Lett. 2012, 4, 489-494. [CrossRef]

39. Liu, M.-P.; Li, W.; Dai, C.; Lam, C.W.K.; Li, Z.; Chen, J.-F.; Chen, Z.-G.; Zhang, W.; Yao, M. Aqueous extract of Sanguisorba officinalis blocks the Wnt/ $\beta$-catenin signaling pathway in colorectal cancer cells. RSC Adv. 2018, 8, 10197-10206. [CrossRef]

40. Re, R.; Pellegrini, N.; Proteggente, A.; Pannala, A.; Yang, M.; Rice-Evans, C. Antioxidant activity applying an improved ABTS radical cation decolorization assay. Free. Radic. Boil. Med. 1999, 26, 1231-1237. [CrossRef]

41. Benzie, I.F.; Strain, J. The Ferric Reducing Ability of Plasma (FRAP) as a Measure of "Antioxidant Power": The FRAP Assay. Anal. Biochem. 1996, 239, 70-76. [CrossRef] [PubMed]

42. Nakai, M.; Fukui, Y.; Asami, S.; Toyoda-Ono, Y.; Iwashita, T.; Shibata, H.; Mitsunaga, T.; Hashimoto, A.F.; Kiso, Y. Inhibitory effects of oolong tea polyphenols on pancreatic lipase in vitro. J. Agric. Food Chem. 2005, 53, 4593-4598. [CrossRef] [PubMed] 
43. Podsędek, A.; Majewska, I.; Redzynia, M.; Sosnowska, D.; Koziolkiewicz, M. In vitro inhibitory effect on digestive enzymes and antioxidant potential of commonly consumed fruits. J. Agric. Food Chem. 2014, 62, 4610-4617. [CrossRef] [PubMed]

44. Nickavar, B.; Yousefian, N. Evaluation of $\alpha$-amylase inhibitory activities of selected antidiabetic medicinal plants. J. Consum. Prot. Food Saf. 2010, 6, 191-195. [CrossRef]

(C) 2020 by the authors. Licensee MDPI, Basel, Switzerland. This article is an open access article distributed under the terms and conditions of the Creative Commons Attribution (CC BY) license (http://creativecommons.org/licenses/by/4.0/). 